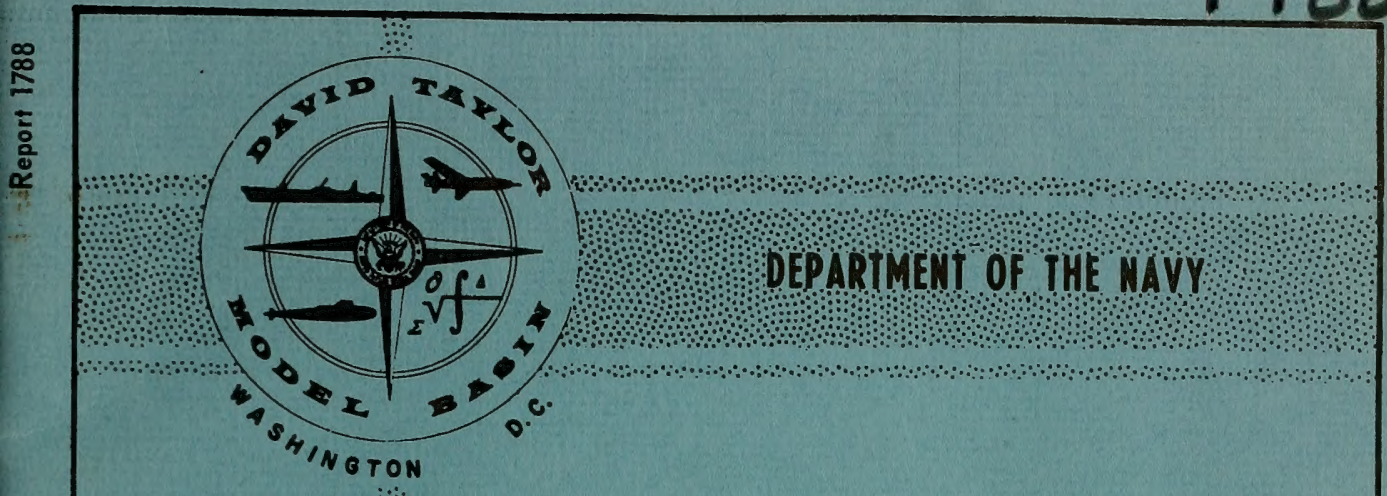

HYOROMECHANICS

0

AERODYNAMICS

0

STRUCTURAL MECHANICS

0

APPLIED

MATHEMATICS

O

STICS AND BRATION
HYDROSTATIC PRESSURE TESTS OF A RING-STIFFENED CYLINDER OF OVAL CROSS SECTION (MAJOR-TO-MINOR AXIS RATIO OF 1.5)

by

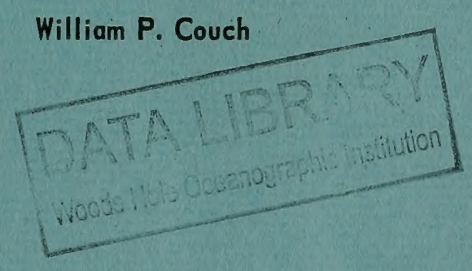

STRUCTURAL MECHANICS LABORATORY RESEARCH AND DEVELOPMENT REPORT

March 1964

Report 1788 


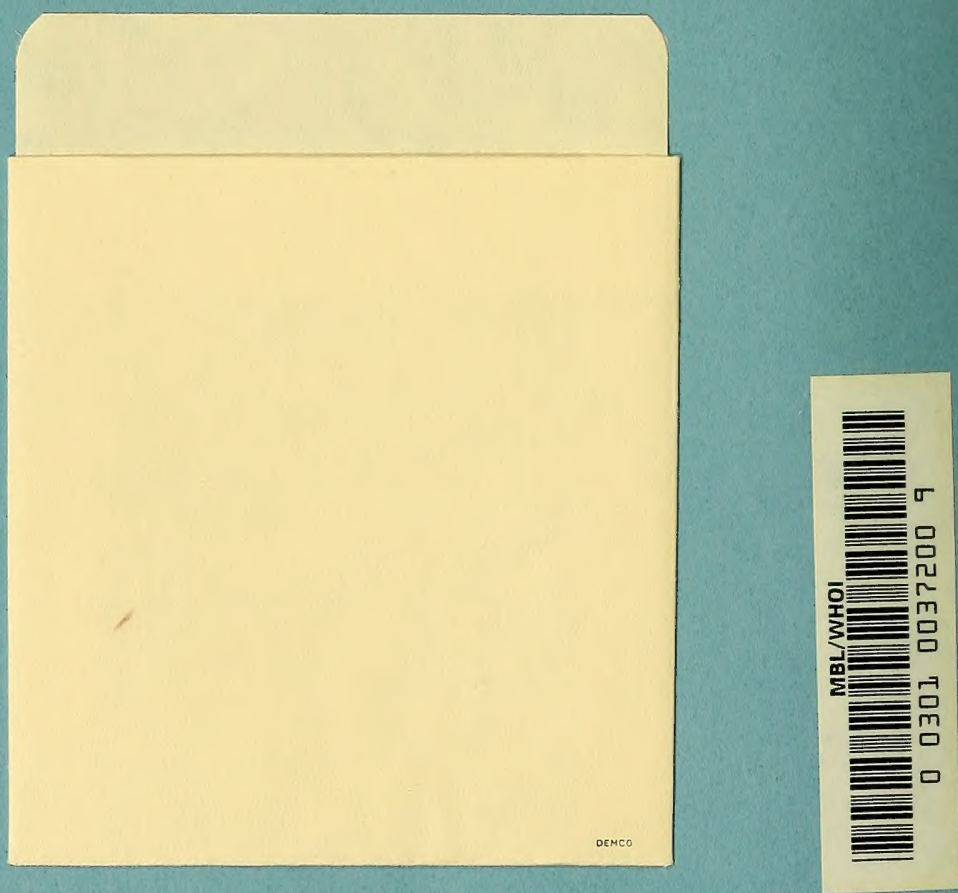




\section{HYDROSTATIC PRESSURE TESTS OF A RING-STIFFENED CYLINDER OF OVAL CROSS SECTION (MAJOR-TO-MINOR AXIS RATIO OF 1.5)}

$$
\text { by }
$$

William P. Couch

March 1964 


\section{TABLE OF CONTENTS}

Page

ABSTRACT

1

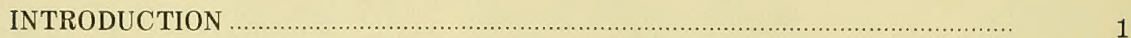

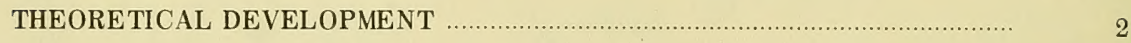

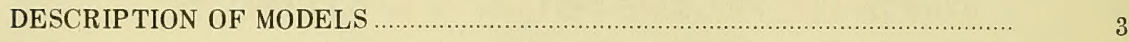

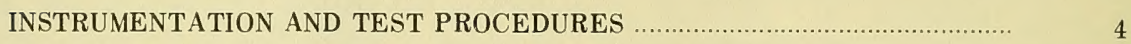

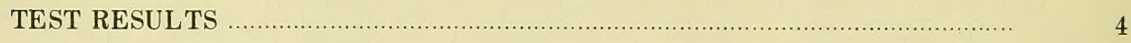

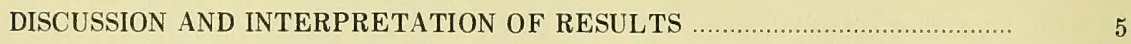

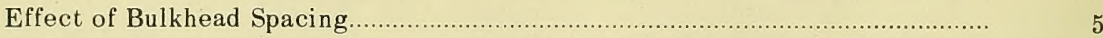

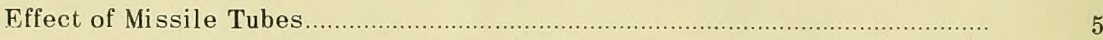

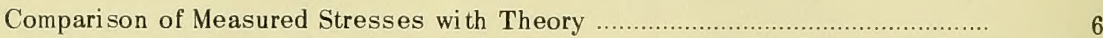

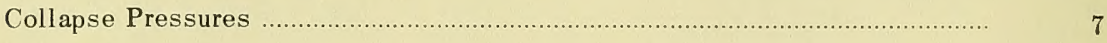

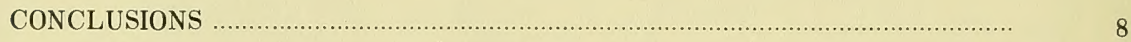

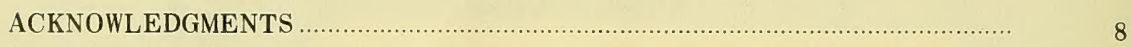

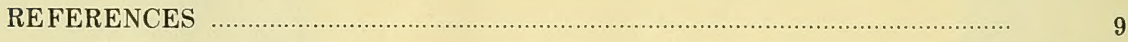




\section{LIST OF FIGURES}

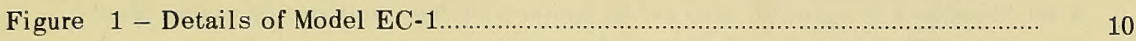

Figure 2 - Formation of Models EC-1A and EC-1B from Model EC-1 ............... 10

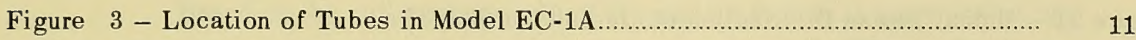

Figure 4 - Structural Details of Tubes Incorporated in Model EC-1A .................. 11

Figure 5- Instrumentation and Measured Strain Sensitivities for

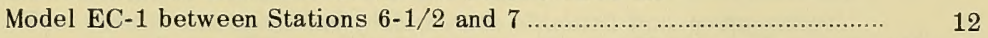

Figure 6-Instrumentation and Measured Strain Sensitivities for End Bays of Model EC-1

Figure 7 - Instrumentation and Measured Strain Sensitivities for Model EC-1, Stations $6-1 / 2$ and 7

Figure 8 - Instrumentation and Measured Strain Sensitivities for Model EC-1B, Frame 3 and Section A-A.

Figure 9 - Instrumentation and Measured Strain Sensitivities for Model EC-1B, Bay $3-1 / 2$.

Figure 10 - Instrumentation and Measured Strain Sensitivities for Model EC-1A.

Figure 11 - Instrumentation and Measured Strain Sensitivities for Model EC-1A, Missile Tube Gages

Figure 12 - Model EC-1A Showing Failure of the Missile Tubes

Figure 13 - Model EC-1A Showing No Apparent Failure to Frame and Shell Structure.

Figure 14 - Model EC-1B after Failure

Figure 15 - Comparison of Measured Midbay Stresses on Inside Surface of a Quadrant of Shell of Models EC-1 and EC-1B

Figure 16 - Comparison of Measured Midbay Stresses on Outside Surface of a Quadrant of Shell of Models EC-1 and EC-1B

Figure 17 - Stress Distribution on Outside Surface of the Shell at the Major Axis

Figure 18 - Stress Distribution on Inside Surface of the Shell at the Major Axis 
Figure 19 - Stress Distribution on Outside Surface of the Shell at the Minor Axis.

Figure 20 - Stress Distribution on Inside Surface of the Shell at the Minor Axis

Figure 21 - Midbay Stress Distribution on Outside Surface of a Quadrant of Shell

Figure 22 - Midbay Stress Distribution on Inside Surface of a Quadrant of Shell

Figure 23 - Circumferential Flange Stress for a Quadrant of Frame 7.

Figure 24 - Axial Membrane and Bending Stresses at the Major Axis

Figure 25 - Axial Membrane and Bending Stresses at the Minor Axis

Figure 26 - Axial Membrane and Bending Stresses at Midbay.

\section{LIST OF TABLES}

Table 1 - Comparison of Measured Stresses to Show Influence of Bulkhead Spacing

Table 2 - Comparison of Measured Stresses to Show Influence of Missile Tubes 


\section{ABSTRACT}

Test results of a ring-stiffened oval cylinder indicate that the use of the local radius of curvature and dimensions of the oval cylinder in a solution for a ring-stiffened circular cylinder will not yield good predictions for the deformations and stresses.

Based on the collapse strength of the models tested, it appears that an oval cylinder designed for deep-depth operation is a very inefficient structure compared to a circular ring-stiffened cylinder of the same weight-displacement ratio.

Test results are compared with results obtained from a theoretical solution recently developed at Polytechnic Institute of Brooklyn for a ringreinforced oval cylinder. The theory treats the case of a shell with uniform thickness; the model, however, was composed of two different shell thicknesses. The theoretical results obtained by using the local shell thickness of the test cylinder in the computation showed good agreement with test results for all circumferential stresses and for the axial bending stresses; the lack of agreement for the axial membrane stresses is attributed to using the local shell thickness in the calculations from a theory which is based on constant thickness.

The critical stresses were found to be much higher for the ringstiffened oval cylinder tested, than for those of an equivalent circular cylinder based on the same radius of curvature. It was also found that tubes or struts placed parallel to the minor axis of the oval cross section appreciably reduced the magnitude of the critical stresses.

\section{INTRODUCTION}

The structural research program of the David Taylor Model Basin includes investigations of new and untried pressure-hull configurations. ${ }^{1}$ A ring-stiffened oval cylinder, for example, may possibly lend itself to a better arrangement of cargo, equipment, machinery, and personnel and accommodate more missile tubes than will conventional structures. Accordingly, a model of such a pressure hull was tested at the Model Basin to compare its structural response and efficiency with that of a ring-stiffened circular cylinder. The test results have provided aid in evaluating the theoretical analysis recently developed at Polytechnic Institute of Brooklyn; in addition, they will assist in guiding future structural research on noncircular pressure hulls.

\footnotetext{
${ }^{1}$ References are listed on page 9.
} 
Later tests with the ring-stiffened oval cylinder incorporated tubes parallel to the minor axis of the oval cross section to determine the effects of this type of structural discontinuity on the overall strength of the structure.

\section{THEORETICAL DEVELOPMENT}

The experimental studies conducted at the Model Basin are closely related to the analytical efforts at Polytechnic Institute of Brooklyn. These latter studies presently constitute a major part of the overall program on transverse strength of submarine structures which is being sponsored jointly by the Office of Naval Research (Code 439) and the Bureau of Ships (Code 442) at that Institute. A number of publications have already appeared which present the findings of the Polytechnic studies; Kempner ${ }^{2}$ summarizes the results through 1961 . It is of interest here to note the more significant results so that structural designers can better understand and appreciate the difference in behavior between circular and noncircular cylindrical pressure hulls.

The first problem amenable to mathematical solution, and one which could provide an insight into the mechanism of deformation of noncircular cylindrical pressure hulls, was that of the simply supported oval cylinder. The analysis developed by Romano and Kempner ${ }^{3}$ indicated that for this case, the use of the local radius of curvature of the oval cross section in the well-known and proven formulas for circular cylinders ${ }^{4}$ gives very good agreement in the stresses and deformations with the "exact" Fourier series solution developed in Reference 3. The results of the analysis of the simply supported oval shell also showed that even with a small eccentricity (ovality), the stresses in an oval shell differ significantly from those in a circular shell of equal length and weight.

The next logical step in the development of adequate theory for the realistic interaction problem in the case of an oval cylinder stiffened with ring frames possessing finite elastic stiffness properties was to investigate the problem of the clamped oval shell. Vafakos, Romano, and Kempner have developed such an analysis, ${ }^{5}$ and their results indicate that the stresses in an oval shell differ significantly from those in an axisymmetric circular shell of equal length and weight. Just as in the case of the simply supported shell, these investigators found that a simple equivalent circular cylinder solution based on the local radius of curvature concept yields good results for the deformations and stresses in a clamped oval shell. The maximum stress was shown to be an axial stress due principally to bending; it occurred at those points of the clamped edges which had the least curvature.

The analysis for the ring-stiffened oval cylinder was obtained by the Polytechnic group by coupling the equation ${ }^{5}$ for the noncircular shell of arbitrary edge conditions with expressions for the displacements and stresses in the oval ring ${ }^{6}$ which is subjected to the interaction load between the ring and shell.

In contrast to the simple analogy of the equivalent circular cylinder using the local radius of curvature concept for the simply supported and clamped oval shells of short length, 
no such simple solution can be hoped for in the case of the cylinder stiffened by elastic rings. The reason for this is that the deformation mechanism is one in which the transverse displacements are radially outward in the region of the major axis and radially inward in the region of the minor axis with respect to the initial undeformed cross section. The elastic-ring analysis indicates such behavior, and it is the development of extreme circumferential bending varying around the periphery which precludes the use of the equivalent cylinder with local radius of curvature concept to predict the deformations and stresses. This is contrary to the cases of the simply supported and clamped oval shells of very short length analysed at Brooklyn Polytechnic Institute in which the transverse displacements are all radially inward around the periphery of the oval cross section.

The analytical results indicate that whereas the area of the stiffening rings plays the dominant role in the shell deformations of a stiffened circular cylinder, the inertia of the ring cross section is of paramount importance in the deformation of a stiffened oval cylinder. This is due to the fact that the axisymmetric nature of the circular cylinder problem precludes the development of tangential (v) displacements whereas the tangential displacements are very important in the oval cylinder problem. These displacements arise as a consequence of a shear flow which develops along the oval periphery to maintain overall equilibrium of the forces. Due to symmetry considerations, this "running shear" is zero at the two extremes of each of the major and minor axes of the oval cross section. This brings up an important problem with regard to the location of the stiffening rings, i.e., whether they are located on the outside or on the inside surface of the noncircular shell will determine the nature of the bending moments caused by the shear flow and the fact that the shell and frame median lines are not truly coincident. This "eccentricity" between the shell and frame median lines will determine the magnitude and sense of the circumferential bending moments and their effect on further distortion of the noncircular shape.

To assist in checking out the analysis developed by the Polytechnic group, the Model Basin provided data ${ }^{7}$ obtained from the initial test of the model presented in this report. Comparison of the theory and Model Basin tests, reported by the Polytechnic group, is given in Reference 8 .

Many of the figures shown in this report have been taken from Reference 8.

\section{DESCRIPTION OF MODELS}

Model EC-1 is an internally stiffened cylinder with a quasi-elliptical cross section. Two radii were used to develop the oval cross section of the model as shown in Figure 1. The shell of the model was fabricated in four strakes of HY-100 steel plating with the diametrical strakes having the same thickness and radius. The yield strength of the thicker shell plating was 96,000 psi and that of the thinner shell plating was 102,000 psi. The model was stiffened with transverse T-frames also fabricated from HY-100 steel plating. Heavier frames were placed at the two ends of the model to preclude premature failure near the rigid closure bulkheads. 
Upon completion of preliminary tests to obtain elastic strain data, the original model which was not taken to failure was cut in half, as shown in Figure 2. Frame 7 was removed and the two halves were designated Model EC-1A and Model FC-1B.

Model EC-1A was modified to study the influence of missile tubes in an oval cylinder. Three tubes were incorporated and aligned in a transverse plane at midlength of the model, as shown in Figure 3. Based on the outside diameter at the minor axis of the oval cylinder, the tubes were designed to be geometrically similar to the missile tubes of FBM submarines; see Figure 4. The tubes were machined from HY-80 forged steel tubing heat-treated to a yield strength of 100,000 psi.

Model EC-1B was used as a control cylinder for EC-1A and also to provide information concerning the influence of reducing the overall length between rigid bulkheads. No missile tubes were inserted in Model EC-1B.

\section{INSTRUMENTATION AND TEST PROCEDURES}

The models were instrumented with foil-type electrical resistance strain gages to study the elastic behavior of the structures and to facilitate interpretation of the collapse pressures. One- and two-element strain gages were used in the instrumentation of the models except in the region near the penetration of Model EC-1A; there, three-element gages were used to determine the direction and magnitude of the principal stresses. Figures 5 to 11 show the location of the strain gages and the strain sensitivity measured by the respective gages.

All three models were tested using oil as the pressurizing medium. Each model was tested in two pressure runs. The maximum pressure of each run was as follows:

\begin{tabular}{c|c|c|c}
\hline \multirow{2}{*}{ Run } & \multicolumn{3}{|c}{ Maximum Pressure, psi } \\
\cline { 2 - 4 } & Model EC-1 & Model EC-1A & Model EC-1B \\
\hline 1 & 500 & 500 & 500 \\
\hline 2 & 620 & $1650 \begin{array}{c}\text { (Tubes } \\
\text { failed) }\end{array}$ & 1670 (collapse)
\end{tabular}

Strain measurements were taken during each of the pressure runs.

\section{TEST RESIJLTS}

Model EC-1 was tested only to obtain elastic strain data. Strain-sensitivity factors determined for each strain gage on this model are given in Figures 5, 6, and 7. The factors are the slope of the linear portion of the pressure-strain curve and are measured in microinches per inch per pound per square inch of pressure. The slope was found for each of the two pressure runs, and an average value was determined for each gage. 
As shown in Figure 12, Model EC-1A sustained a pressure of 1650 psi prior to failure of the missile tubes. There was no visible damage to either the shell or frames as can be seen in Figure 13, which indicates that the tubes were not adequately designed to withstand the loads imposed upon them by the oval shell.

Model EC-1B, a model of the same length as EC-1A but without missile tubes, failed at a pressure of $1670 \mathrm{psi}$. Failure appeared to be attributed to a tendency of the oval cross section to "flatten out"; see Figure 14.

Strain-sensitivity factors for each gage on Models EC-1A and EC-1B are given in Figures 8 to 11 .

\section{DISCUSSION AND INTERPRETATION OF RESULTS}

\section{EFFECT OF BULKHEAD SPACING}

Table 1 compares the measured stresses obtained from the original-length model (EC-1) and a half-length model (EC-1B). The circumferential flange stresses and the Hencky-Von Mises shell stresses (midbay) given in Table 1 for the major and minor axes of both models represent average values determined from strain gages located at similar locations. It can be seen that the Hencky-Von Mises shell stresses near the region of the major axis and the flange stresses were appreciably reduced by closing the distance between rigid bulkheads. Figures 15 and 16 compare both the circumferential and longitudinal stresses for a quadrant of the shell at midbay of Models EC- 1 and EC-1B. The abscissa $\theta$ in these figures is the angle which a normal to the median surface of its shell in Figure 1 makes with the major axis. It can be seen from Figures 15 and 16 that the shell stresses measured on Model EC-1B were appreciably influenced by the rigid closure bulkheads.

\section{EFFECT OF MISSILE TUBES}

Table 2 compares the measured stresses obtained from the oval cylinder with missile tubes (EC-1A) and a similar cylinder without missile tubes (EC-1B). Stresses given for Model EC-1A are those away from the region of the missile-tube penetrations. It can be seen that the "strut" action afforded by the tubes reduced the overall stresses of the oval cylinder considerably.

The highest stresses measured on Model EC-1A were not those shown in Table 2. Higher stresses were measured on the inside surface of the shell at the intersection of the center tube; a principal-stress value of $-71.9 \mathrm{psi} / \mathrm{psi}$ was determined from strain gages located in this region. Another area of high stress was that measured on the missile tubes away from the shell intersection; an axial stress of $-63.3 \mathrm{psi} / \mathrm{psi}$ was measured on the center tube. It is interesting to note that neither of these stresses was as high as the highest measured stresses which were found on the frame flange of the original model (EC-1); see Table 1. 
The axial compressive stresses of $-63.3 \mathrm{psi} / \mathrm{psi}$ measured at midlength of the missile tubes were slightly above the yield strength of the material when the tubes failed. Such high stresses have not been previously observed in the missile tubes of circular pressure hulls and can be attributed to the resistance of the tubes to a tendency of the oval cylinder to become more elliptical under loading. It appears that for a tube arrangement such as that used in Model EC-1A, thicker walled tubes are required for an oval cylinder than for an equivalent circular cylinder of the same radius of curvature.

\section{COMPARISON OF MEASURED STRESSES WITH THEORY}

The solid-line curves for the stress sensitivities shown in Figures 17 to 26 were taken from Reference 8 and represent the results of using the local thickness of the ring-stiffened oval cylinder of Figure 1 in the theoretical solution obtained for an oval shell of uniform thickness. The work done by Polytechnic Institute of Brooklyn, which led to the analytical results shown in their figures, was discussed in a previous section of this report. The experimental points appearing in the figures were obtained from strain-gage measurements during the test of Model EC-1. The dashed curves shown in Figures 17 to 23 represent the stress distribution based on using the local radius of curvature and shell thickness of the oval cross section in the analysis of Von Sanden and Gunther ${ }^{9}$ for a ring-stiffened circular cylinder. This type of approximate solution has been shown in References 3 and 5 to yield good results for simply and clamped supported short oval cylinders. However, as has been indicated in Reference 5 and from an inspection of these figures, an equivalent circular cylinder solution based on the local radius of curvature concept will not yield good results for the deformations and stresses of an oval cylinder stiffened by elastic rings.

Figures 17 and 18 are plots of the circumferential and longitudinal stress distributions along the outside and inside surfaces of the shell at the major axis. Figures 19 and 20 are corresponding plots at the minor axis. Figures 21 and 22 show the midbay stresses for a quadrant of the oval shell; Figure 23 shows the circumferential flange stresses in the ring. The abscissa $\theta$ in these latter figures is the angle which the local normal to the median surface of the shell makes with the major axis.

The solid curves in Figures 17 to 23, which are based on the solution developed by Polytechnic Institute of Brooklyn in which the local shell thickness was used, show excellent agreement with the measured circumferential stresses $\sigma_{\theta}$. The theoretical longitudinal stresses $\sigma_{x}$ (shown in Figures 17 to 22) differ from the test results by a translation in which the theoretical stresses are too low at the major axis and too high at the minor axis. Figures 24 to 26 isolate the discrepancy between the theoretical and measured stresses $\sigma_{x}$. In these latter figures, the stresses $\sigma_{x}$ have been separated into membrane and bending components by the following relationships: 


$$
\begin{aligned}
& \left(\sigma_{x}\right)_{\text {membrane }}=\frac{1}{2}\left[\left(\sigma_{x}\right)_{\text {inner }}+\left(\sigma_{x}\right)_{\text {outer }}\right] \\
& \left(\sigma_{x}\right)_{\text {bending }}=\frac{1}{2}\left[\left(\sigma_{x}\right)_{\text {inner }}-\left(\sigma_{x}\right)_{\text {outer }}\right]
\end{aligned}
$$

It can be seen from Figures 24 to 26 that the theoretical values for $\left(\sigma_{x}\right)_{\text {bending }}$ agree well with the measured values and that the discrepancy between theoretical and measured stresses $\sigma_{x}$ is due to the theoretical values for $\left(\sigma_{x}\right)_{\text {membrane }}$. Their poor agreement is attributed to the use of two different local shell thicknesses (see Figure 1) in a solution for an oval cylinder of uniform thickness subjected to hydrostatic pressure. The results of such a calculation lead to two different axial contractions, with the thinner shell contracting more than the thicker shell. If it is assumed that both portions of the shell contract the same (as may be the case for the models tested) and that the net end load does not change, then relative to the calculated contractions, the thinner shell would have to be stretched and the thicker shell compressed. This would increase the axial membrane stress in the thin shell and decrease (algebraically) the corresponding stress in the thick shell. Such a correction would shift the theoretical curves for $\sigma_{x}$ toward the experimental results.

\section{COLLAPSE PRESSURES}

It was found from previous hydrostatic tests ${ }^{10}$ of ring-stiffened circular cylinders which failed by axisymmetric yielding that experimental collapse pressures agreed best with theory based on the Hencky-Von Mises criterion of failure and allowing for the plastic reserve strength after initiation of yielding. Collapse pressures computed from the Model Basin plastic hinge theory ${ }^{11}$ applied very well with circular cylinders fabricated from steels exhibiting a plateau-type stress-strain curve. Based on the local radius of curvature for the oval cylinder shown in Figure 1, plastic-hinge collapse pressures of 2356 and 3049 psi were computed for the large and small radial section of the model, respectively. Comparison of these pressures with the experimental collapse pressure of 1670 psi for Model EC-1B shows that the strength of the oval cylinder tested is lower than a comparable circular cylinder of the same dimensions and radius of curvature.

Another interesting point worthy of mentioning is the fact that an oval cylinder has less enclosed volume than a circular cylinder of equal peripheral length. By virtue of this fact, the ratio of weight of pressure hull to weight of displaced water of the hull is very high for Model EC-1. A weight-displacement ratio of 0.598 was computed for this model. Based on least-weight calculations, a circular cylinder with the same weight-displacement ratio and fabricated from HY-100 steel would have a collapse pressure on the order of $4000 \mathrm{psi}$. This can be compared with the collapse pressure of Model EC-1B which was only 1670 psi. Thus, on a strength-weight/displacement basis, the test of Model EC-1B lends further evidence that a ring-stiffened oval cylinder with a major to minor axis ratio of 1.5 is a very inefficient structure when compared to a circular cylinder. 


\section{CONCLUSIONS}

1. Test results indicate that the stresses and deformations of an oval cylinder stiffened by elastic rings cannot be predicted by an equivalent circular cylinder solution based on the same radius of curvature.

2. Based on the following results, it appears that a ring-stiffened oval cylinder designed for deep-depth operation is a very inefficient structure when compared with a ring-stiffened circular cylinder:

a. Plastic hinge collapse pressures of 2356 and 3049 psi were computed for the large-radius and small-radius sections of the oval cylinder, respectively. These pressures were computed by considering an equivalent circular cylinder with the same local radius of curvature as the oval cylinder which had a collapse pressure of only 1670 psi.

b. The weight-displacement ratio of the oval cylinder was 0.598. Based on least-weight calculations, a circular cylinder with the same weight-displacement ratio and fabricated from the same material (HY-100 steel) would have a collapse pressure on the order of $4000 \mathrm{psi}$ as compared to the collapse pressure of $1670 \mathrm{psi}$ for the model.

3. Additional studies, based on theoretical knowledge now available, may indicate that for shallow-depth operation the oval cylinder may lend itself to a better distribution of cargo, equipment, machinery, and personnel and may accommodate more missile tubes than a ringstiffened circular oylinder.

4. Test results indicate that the theoretical solution recently developed at Polytechnic Institute of Brooklyn will yield good predictions for the deformations and stresses of ringstiffened oval cylinders with uniform shell thickness.

5. In the ring-stiffened oval cylinder tested, critical stresses were reduced as much as 50 percent by incorporating tubes parallel to the minor axis of the oval cross section. However, thicker walled tubes would be required for the oval cylinder than for an equivalent circular cylinder of the same radius of curvature and dimensions.

\section{ACKNOWLEDGMENTS}

The author is indebted to Messrs. J.G. Pulos and Kenneth Hom for their guidance and suggestions.

The author would also like to acknowledge the close cooperation received from Polytechnic Institute of Brooklyn in the theoretical phase of this study. 


\section{REFERENCES}

1. "Bureau of Ships Long Range Research and Development Plan, Volume I and II, Chapter 4 (Hulls)," (Mar 1962) CONFIDENTIAL.

2. Kempner, J., "Summary of Research on Reinforced and Unreinforced Cylindrical Shells, 1952-1961," Polytechnic Institute of Brooklyn Report PIBAL 598 (Feb 1962).

3. Romano, F.J. and Kempner, J., "Stress and Displacement of a Simply Supported Non-Circular Cylindrical Shell Under Lateral Pressure," Polytechnic Institute of Brooklyn Report PIBAL 415 (Jul 1958).

4. Timoshenko, S., "Theory of Plates and Shells," McGraw-Hill Book Co., Inc., New York (1940).

5. Vafakos, W.P., Romano, F.J., and Kempner, J., "Stress and Displacement Analysis of Clamped Non-Circular Cylindrical Shells Under Hydrostatic Pressure," Polytechnic Institute of Brooklyn Report PIBAL 594 (Jun 1961).

6. Vafakos, W.P., “Deep Oval Ring Equations with Simplifications for Application to Ring-Shell Configurations," Polytechnic Institute of Brooklyn Report PIBAL 678 (Feb 1964).

7. Couch, W.P. and Pulos, J. G., "Progress Report - Experimental Stresses and Strains in a Ring-Stiffened Cylinder of Oval Cross Section (Major-to-Minor Axis Ratio of 1.5)," David Taylor Model Basin Report 1726 (Mar 1963).

8. Kempner, J., Vafakos, W.P., and Nissel, N., "Pressurized Ring-Reinforced Oval Cylinder - Comparison of Theory and DTMB Tests," Polytechnic Institute of Brooklyn Report PIBAL 671 (Sep 1963).

9. Von Sanden, K. and Gunther, K., "The Strength of Cylindrical Shells, Stiffened by Frames and Bulkheads, under Uniform External Pressure on All Sides," Werft and Reederei (1920); Vol. 9, pp. 189-198; Vol. 10, pp. 216-221. Also David Taylor Model Basin Translation 38 (Mar 1952).

10. Pulos, J.G. and Hom, K., "Empirical Curves for Determining the Collapse Strength of Stiffened Circular Cylinders Subjected to External Hydrostatic Pressure," David Taylor Model Basin Report C-1243 (Jan 1962) CONFIDENTIAL.

11. Lunchick, M.E., "Yield Failure of Stiffened Cylinders under Hydrostatic Pressure," David Taylor Model Basin Report 1291 (Jan 1959). 

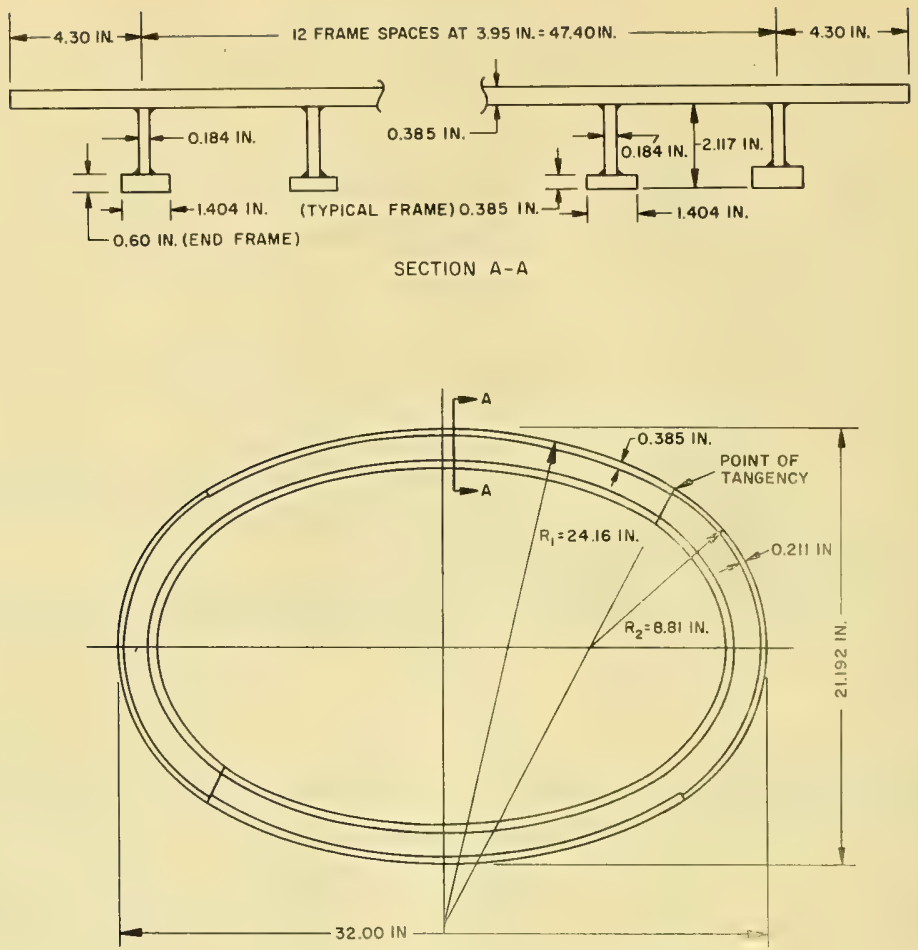

Figure 1 - Details of Model EC-1

CIRCULAR PRESSURE TANK ADAPTER

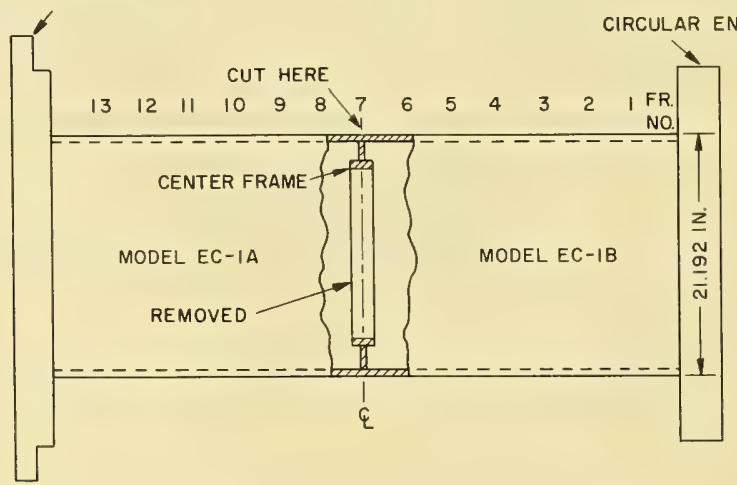

Figure 2 - Formation of Models EC-1A and EC-1B from Model EC-1 


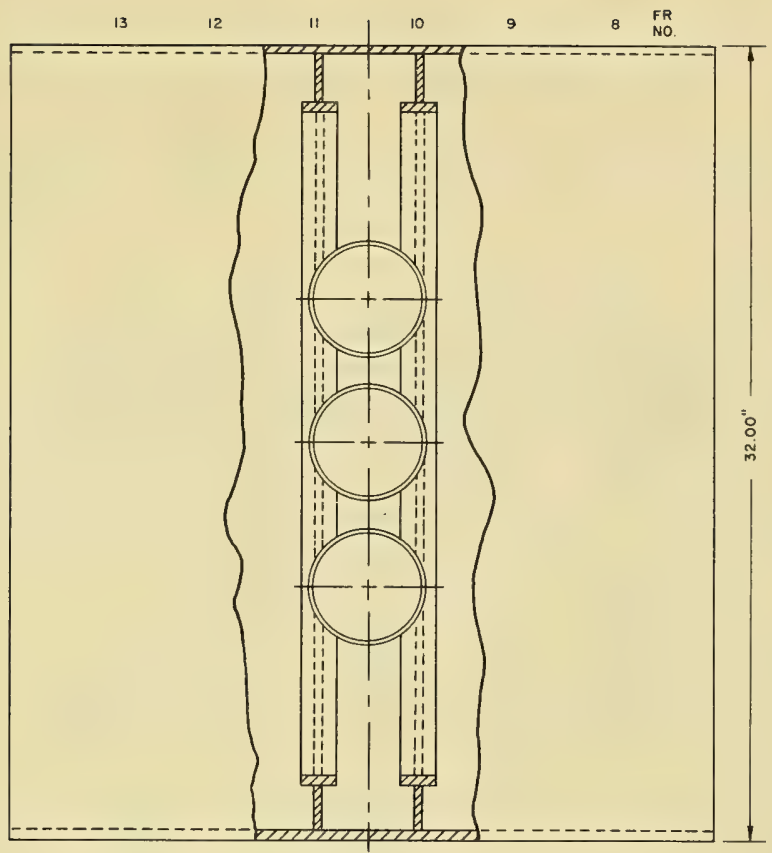

Figure 3 - Location of Tubes in Model EC-1A

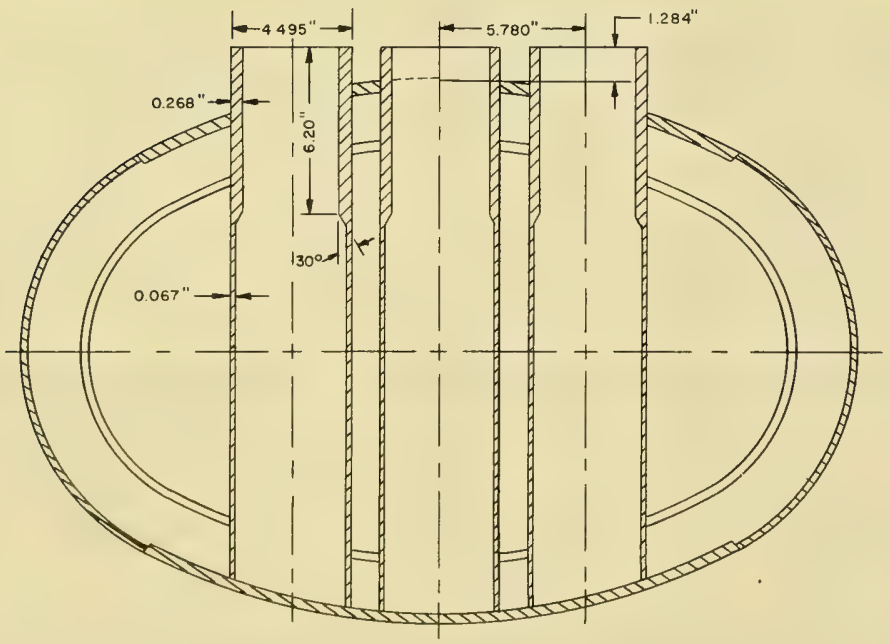

Figure 4 - Structural Details of Tubes Incorporated in Model EC-1A 
FRAME NUMBERS
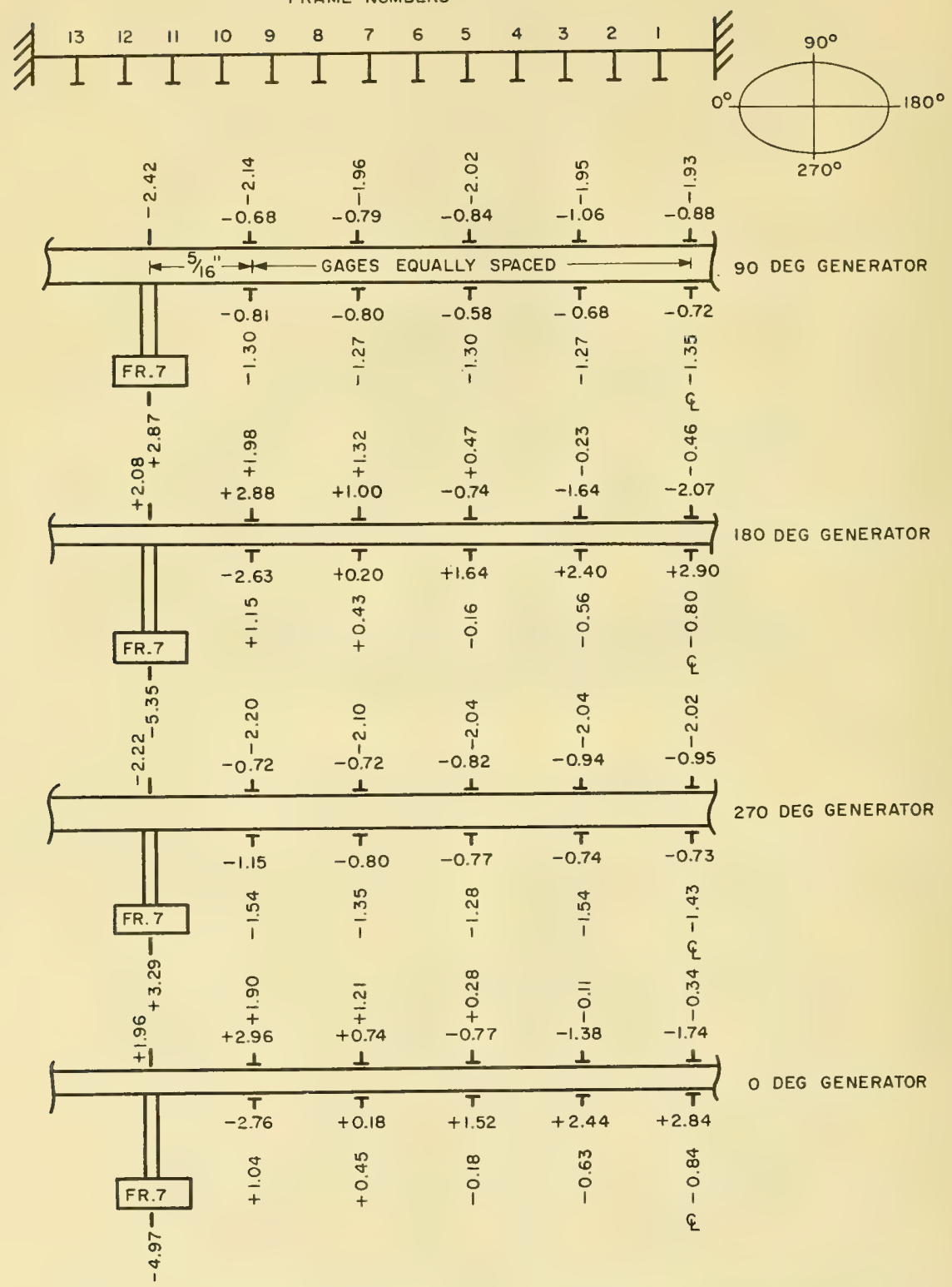

270 DEG GENERATOR

O DEG GENERATOR

Figure 5 - Instrumentation and Measured Strain Sensitivities for Model EC-1 between Stations $6-1 / 2$ and 7 


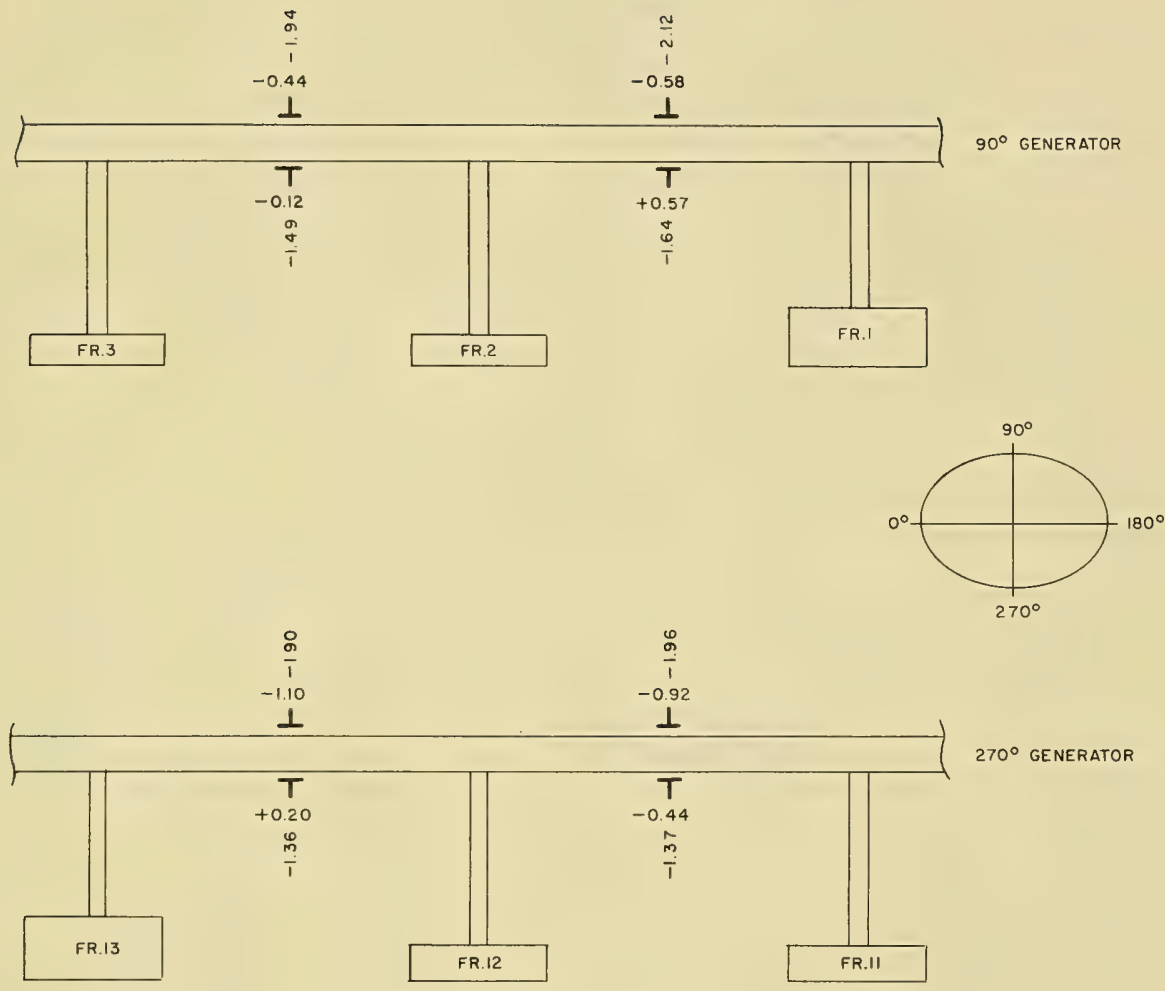

Figure 6 - Instrumentation and Measured Strain Sensitivities for End Bays of Model EC-1 


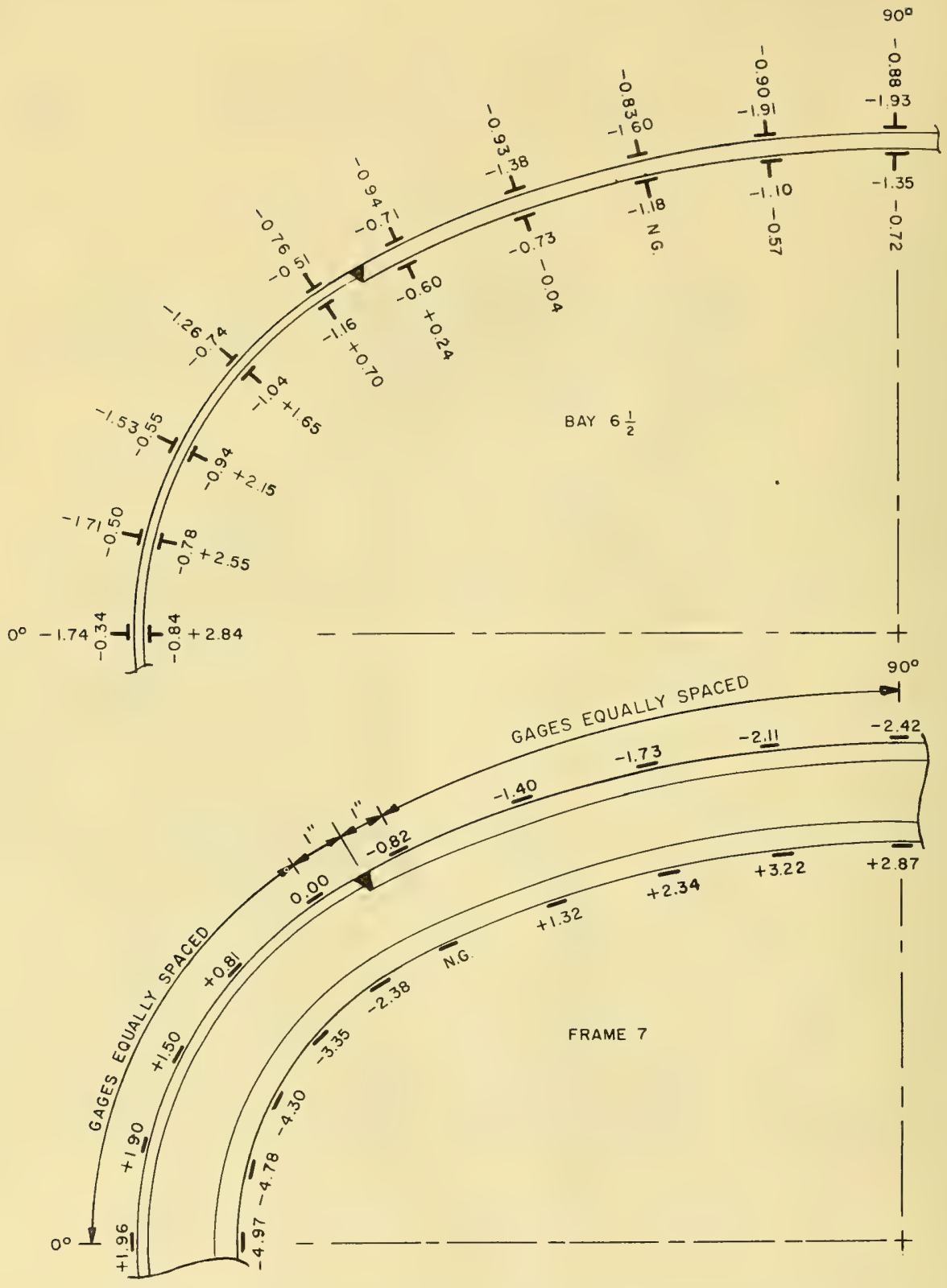

Figure 7 - Instrumentation and Measured Strain Sensitivities for Model EC-1 Stations $6-1 / 2$ and 7 


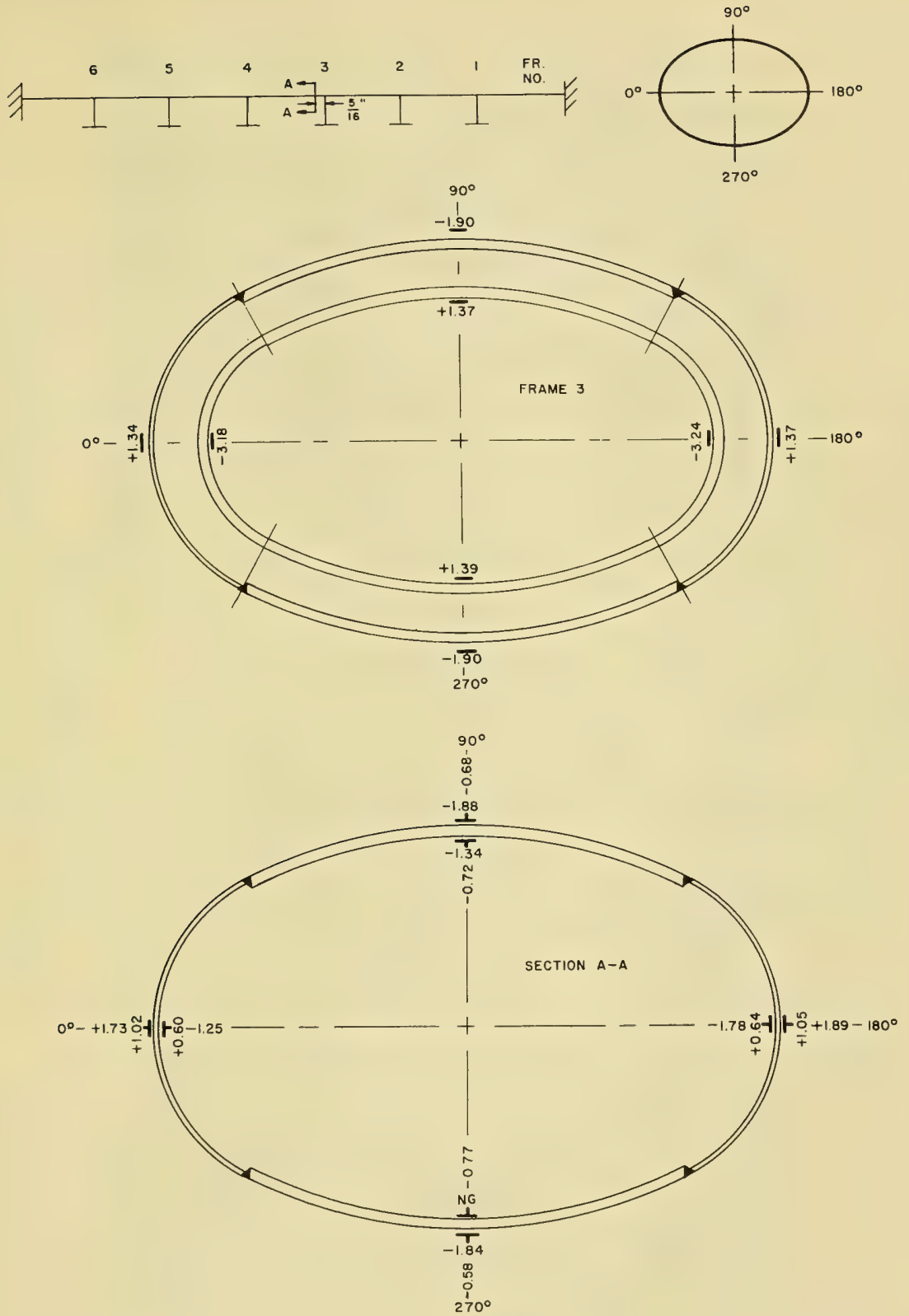

Figure 8 - Instrumentation and Measured Strain Sensitivities for Model EC-1B Frame 3 and Section A-A 


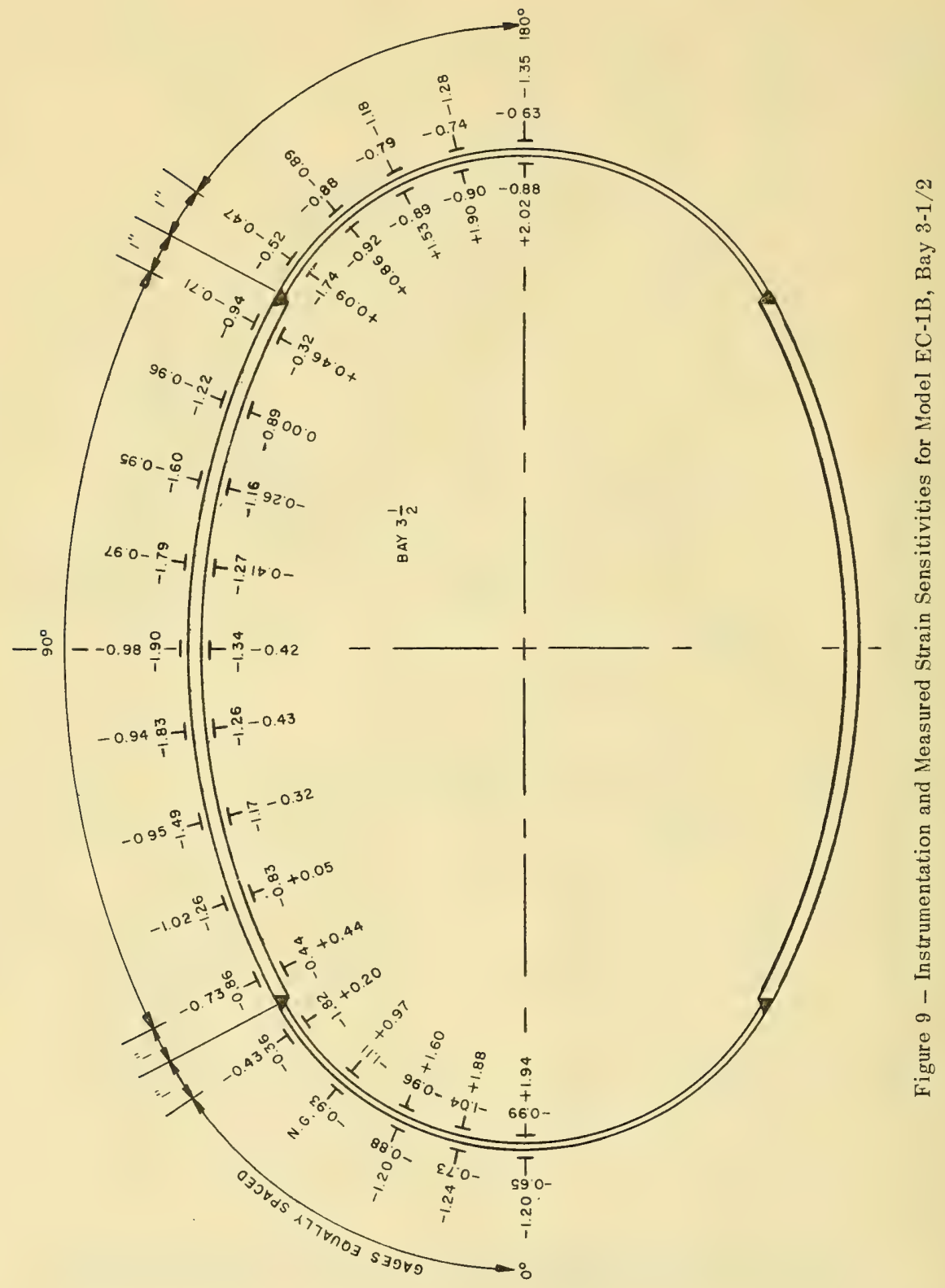




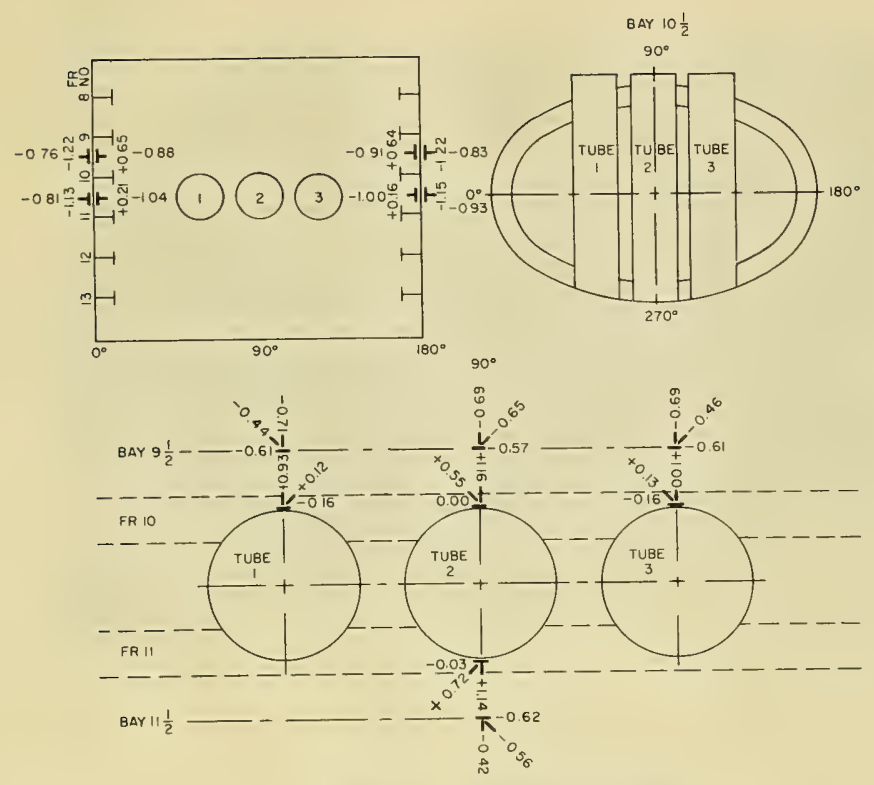

Figure 10a - Outside Shell Gages

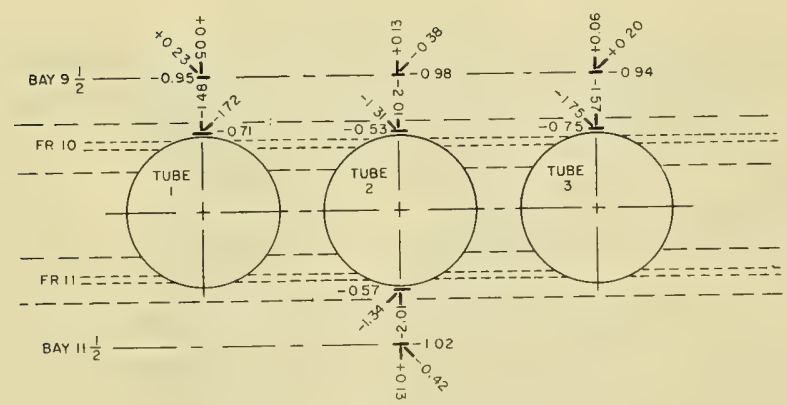

Figure 10b - Inside Shell Gages

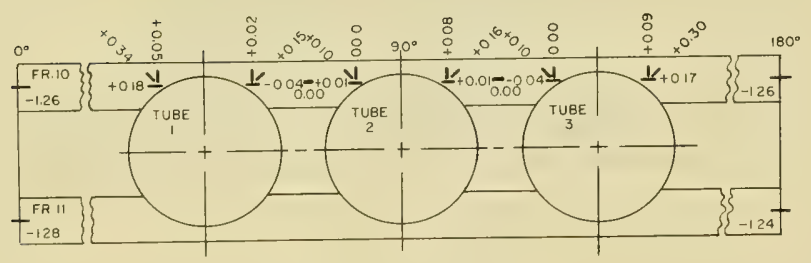

Figure 10c - Flange Gages

Figure 10 - Instrumentation and Measured Strain Sensitivities for Model EC-1A 


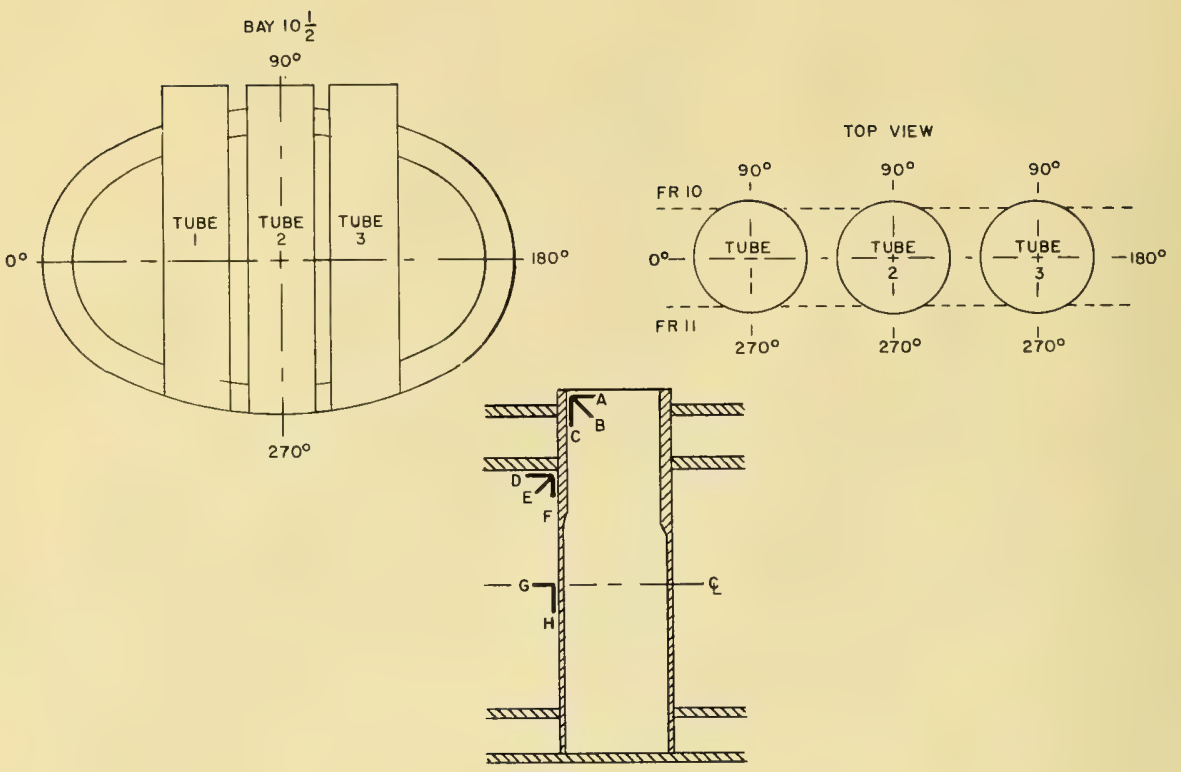

\begin{tabular}{|c|c|c|c|c|c|c|c|c|c|}
\hline Tube & $\begin{array}{c}\text { Orientation } \\
\text { deg }\end{array}$ & A & B & C & D & $E$ & $\mathrm{~F}$ & G & $\mathrm{H}$ \\
\hline \multirow{4}{*}{1} & 0 & -0.96 & -0.33 & +0.57 & - & - & - & - & - \\
\hline & 90 & - & - & - & - & - & - & - & $=$ \\
\hline & 180 & -1.09 & 0.00 & +1.01 & - & - & - & - & $=$ \\
\hline & 270 & - & - & - & $N G$ & $N G$ & $N G$ & +0.06 & -1.82 \\
\hline \multirow{4}{*}{2} & 0 & -0.98 & -0.42 & +0.76 & - & - & - & - & - \\
\hline & 90 & -0.23 & +0.02 & +0.18 & -0.09 & -0.17 & -0.24 & 0.00 & -1.69 \\
\hline & 180 & -1.05 & -0.21 & +0.75 & - & - & - & - & - \\
\hline & 270 & -0.12 & +0.32 & +0.99 & -0.07 & -0.15 & -0.24 & +0.10 & -1.70 \\
\hline \multirow{4}{*}{3} & 0 & -1.12 & -0.10 & +0.99 & - & - & - & - & - \\
\hline & 90 & -0.09 & 0.00 & +0.13 & - & - & - & $=$ & - \\
\hline & 180 & -0.88 & -0.35 & +0.33 & - & - & - & - & - \\
\hline & 270 & -0.17 & +0.05 & +0.29 & $N G$ & $N G$ & $N G$ & 0.00 & -1.92 \\
\hline
\end{tabular}

Figure 11 - Instrumentation and Measured Strain Sensitivities for Model EC-1A, Missile Tube Gages 


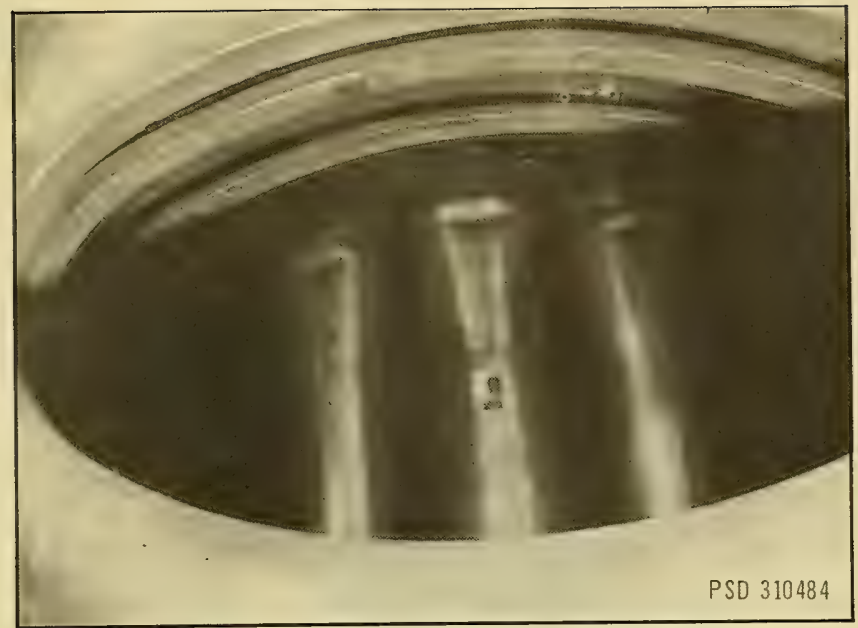

Figure 12 - Model EC-11 Showing Failure of the Missile Tubes

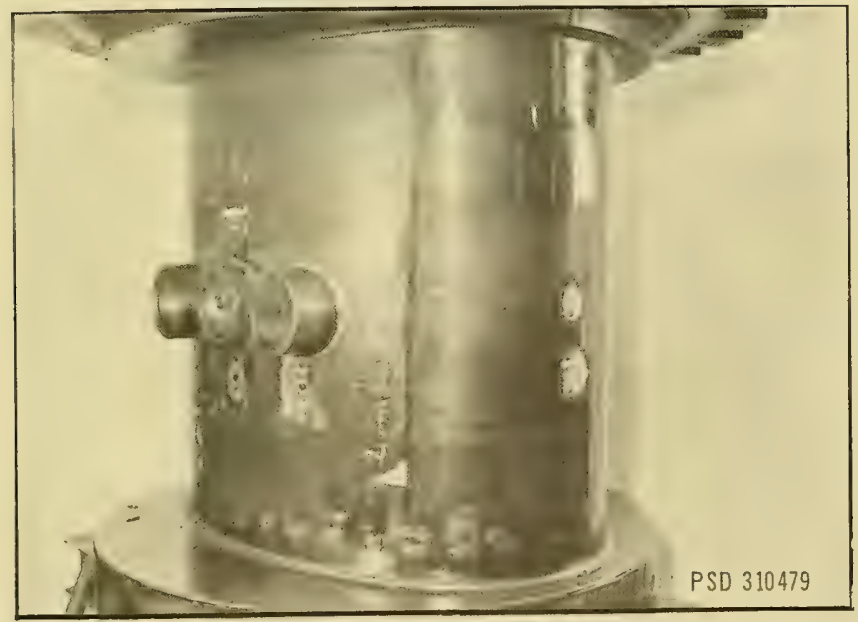

Figure 13 - Model EC-1. Showing No Apparent Failure to Frame and Shell Structure 


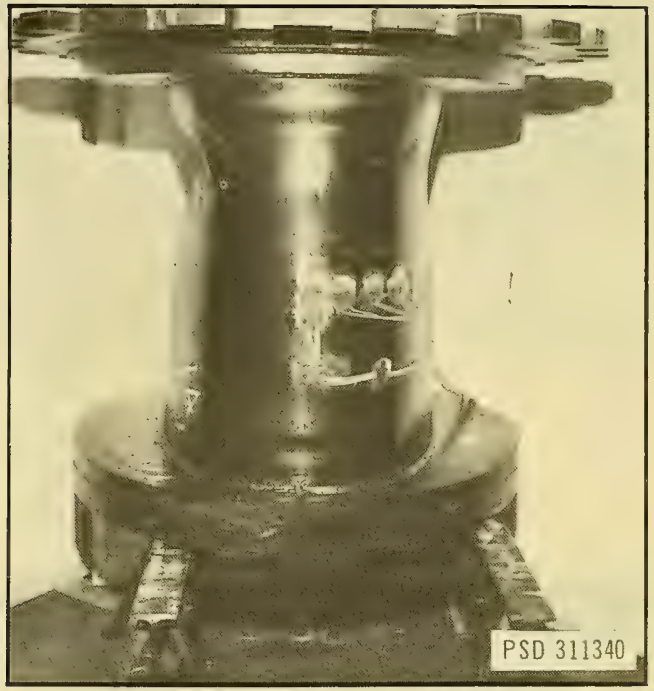

Figure 14 - Model EC-1B after Failure 


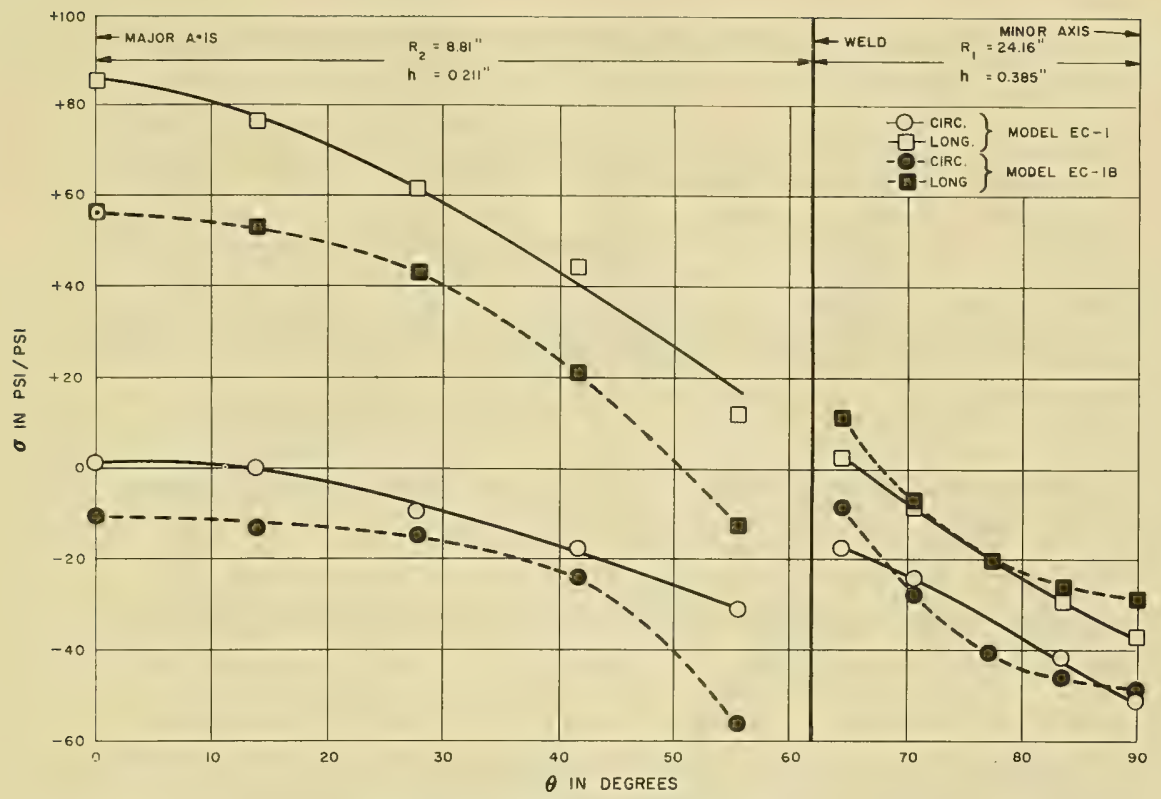

Figure 15 - Comparison of Measured Midbay Stresses on Inside Surface of a Quadrant of Shell of Models EC-1 and EC-1B

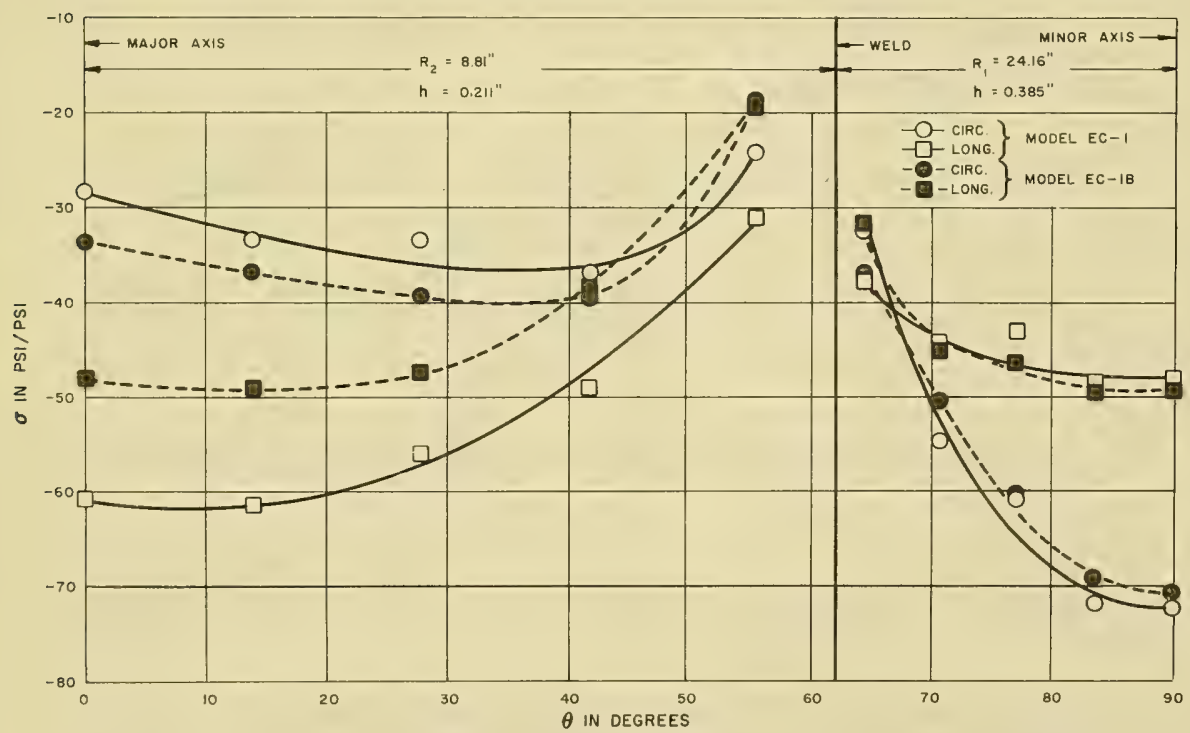

Figure 16 - Comparison of Measured Midbay Stresses on Outside Surface of a Quadrant of Shell of Models EC- 1 and EC-1B 


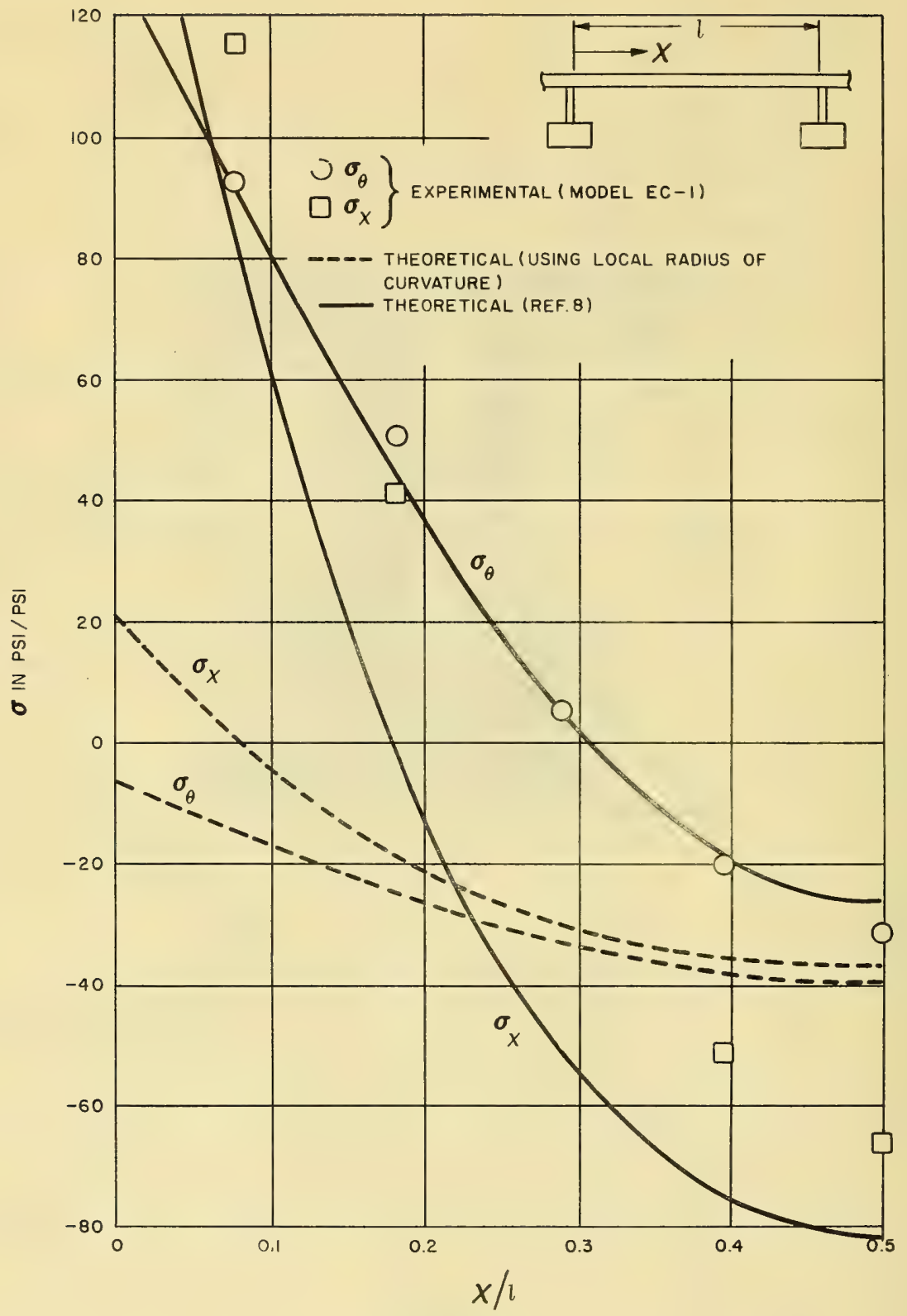

Figure 17 - Stress Distribution on Outside Surface of the Shell at the Major Axis 


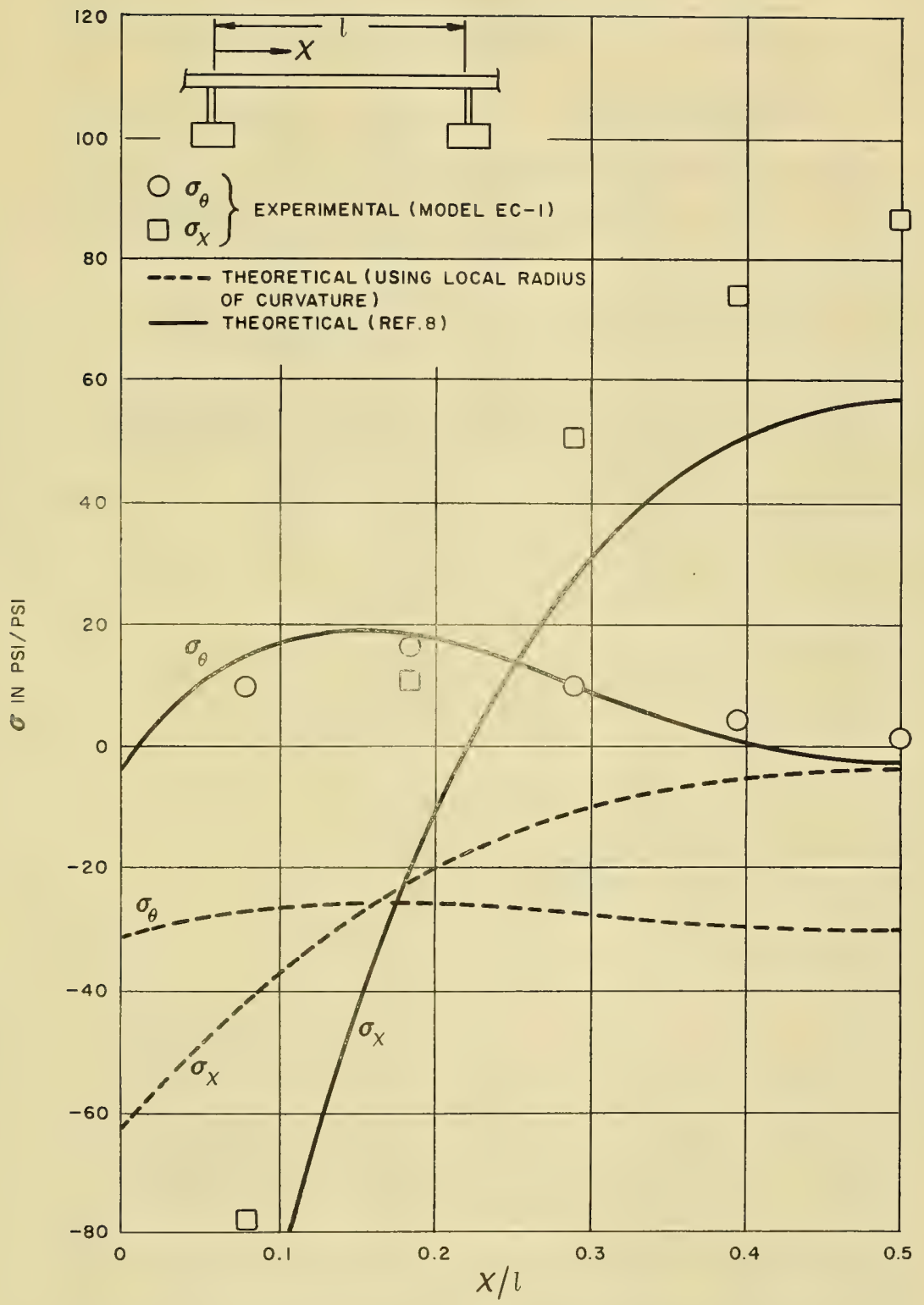

Figure 18 - Stress Distribution on Inside Surface of the Shell at the Major Axis 


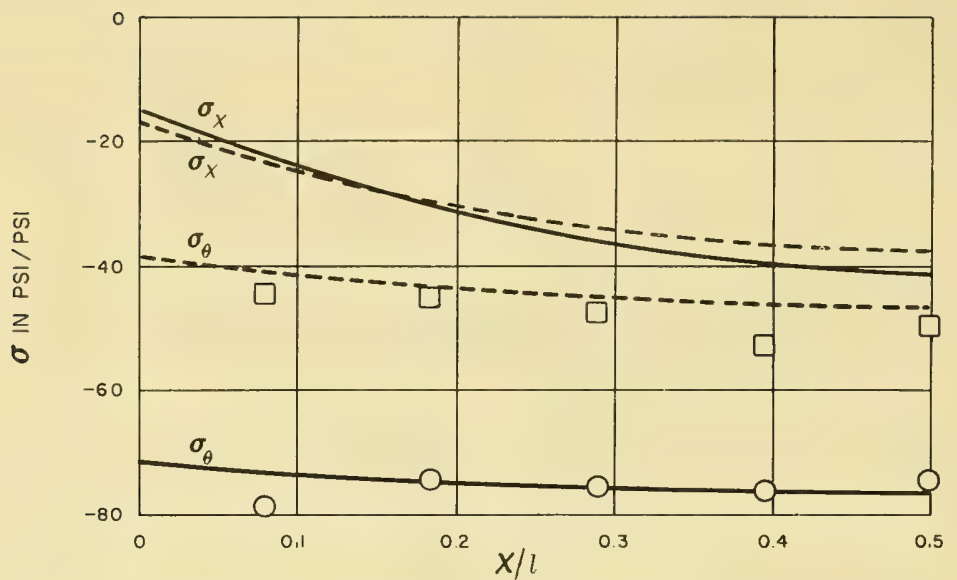

Figure 19 - Stress Distribution on Outside Surface of the Shell at the Minor Axis

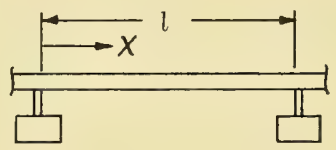

$\left.\begin{array}{ll}O & \sigma_{\theta} \\ \square & \sigma_{x}\end{array}\right\}$ EXPERIMENTAL (MODEL EC-1)

- - THEORETICAL (USING LOCAL RADIUS OF CURVATURE)

- THEORETICAL (REF.8)

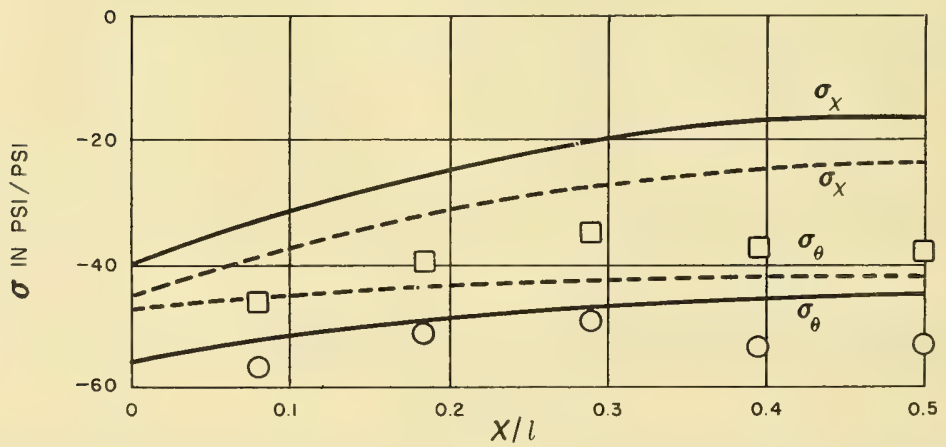

Figure 20 - Stress Distribution on Inside Surface of the Shell at the Minor Axis 


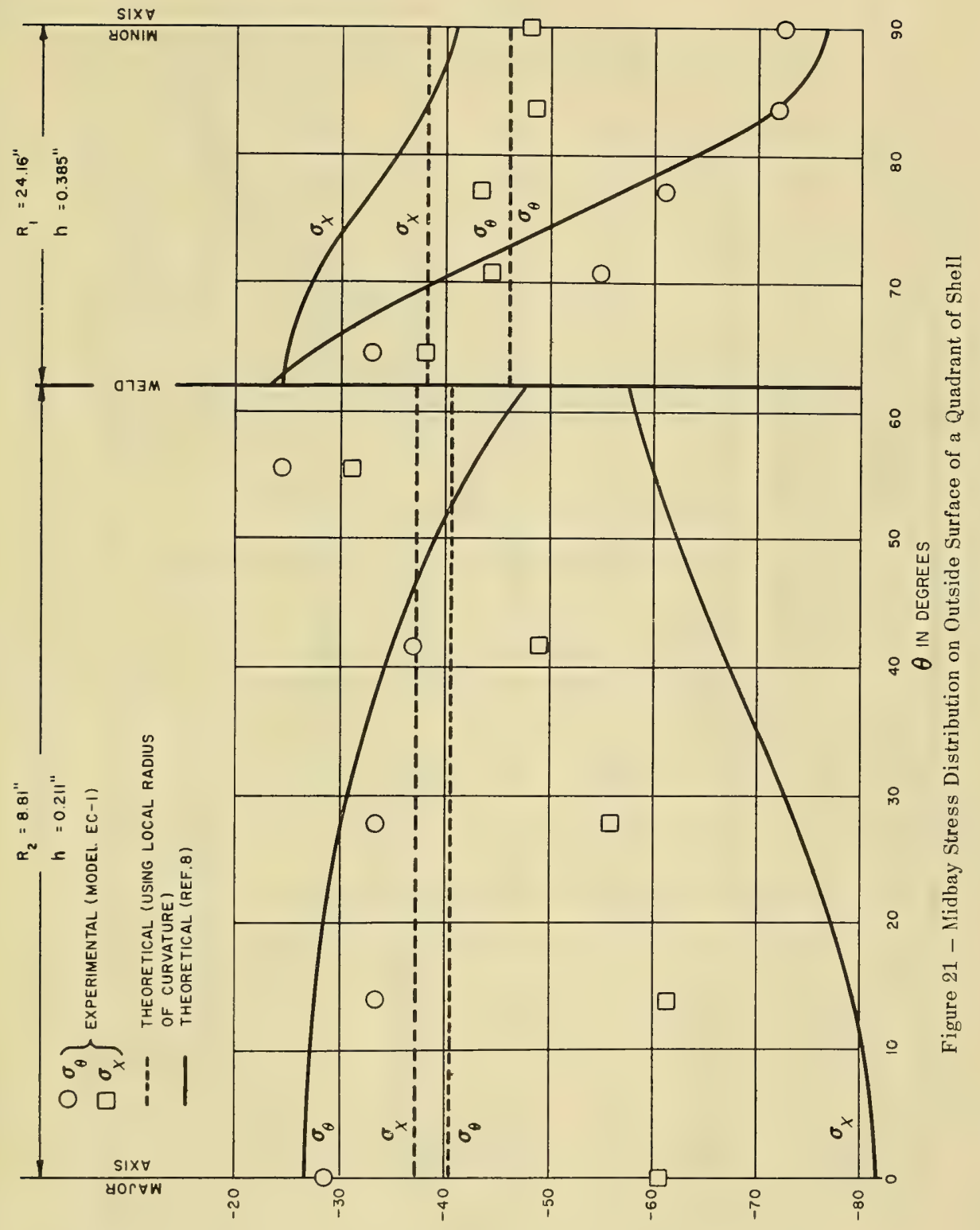

ISd/ISd NI 0 


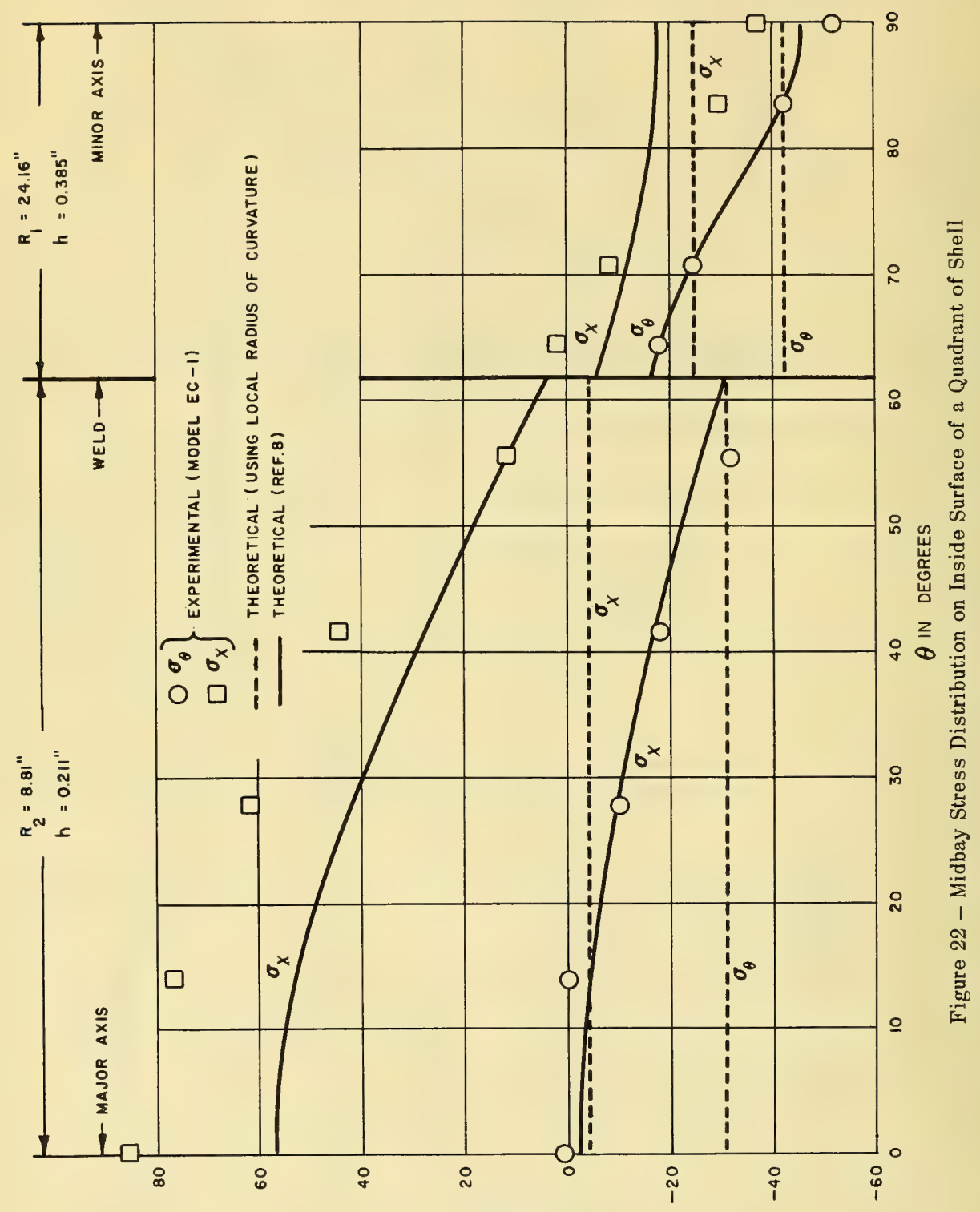

ISd/ISd NI $D$ 


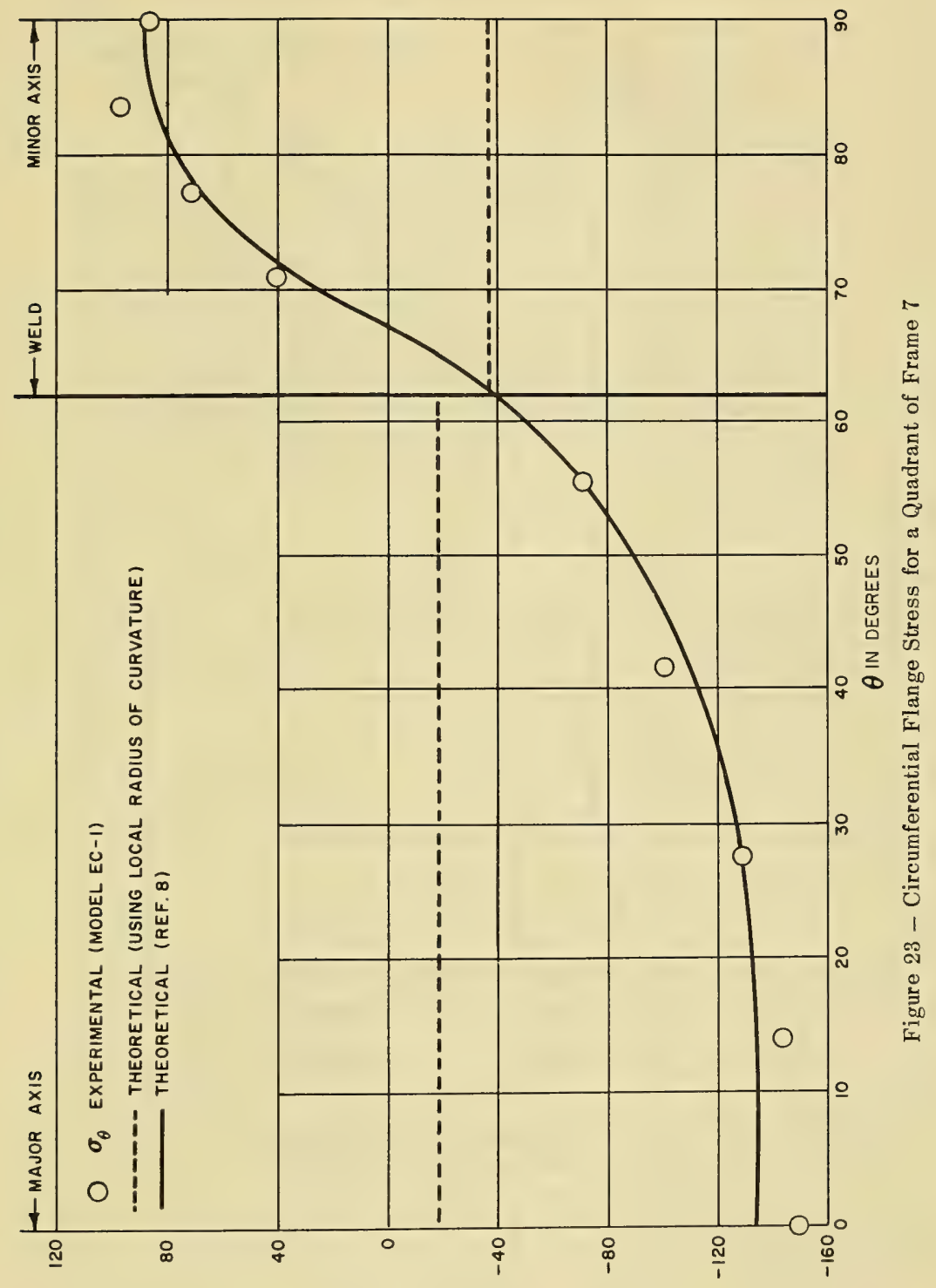

ISd/ISd NI 0 


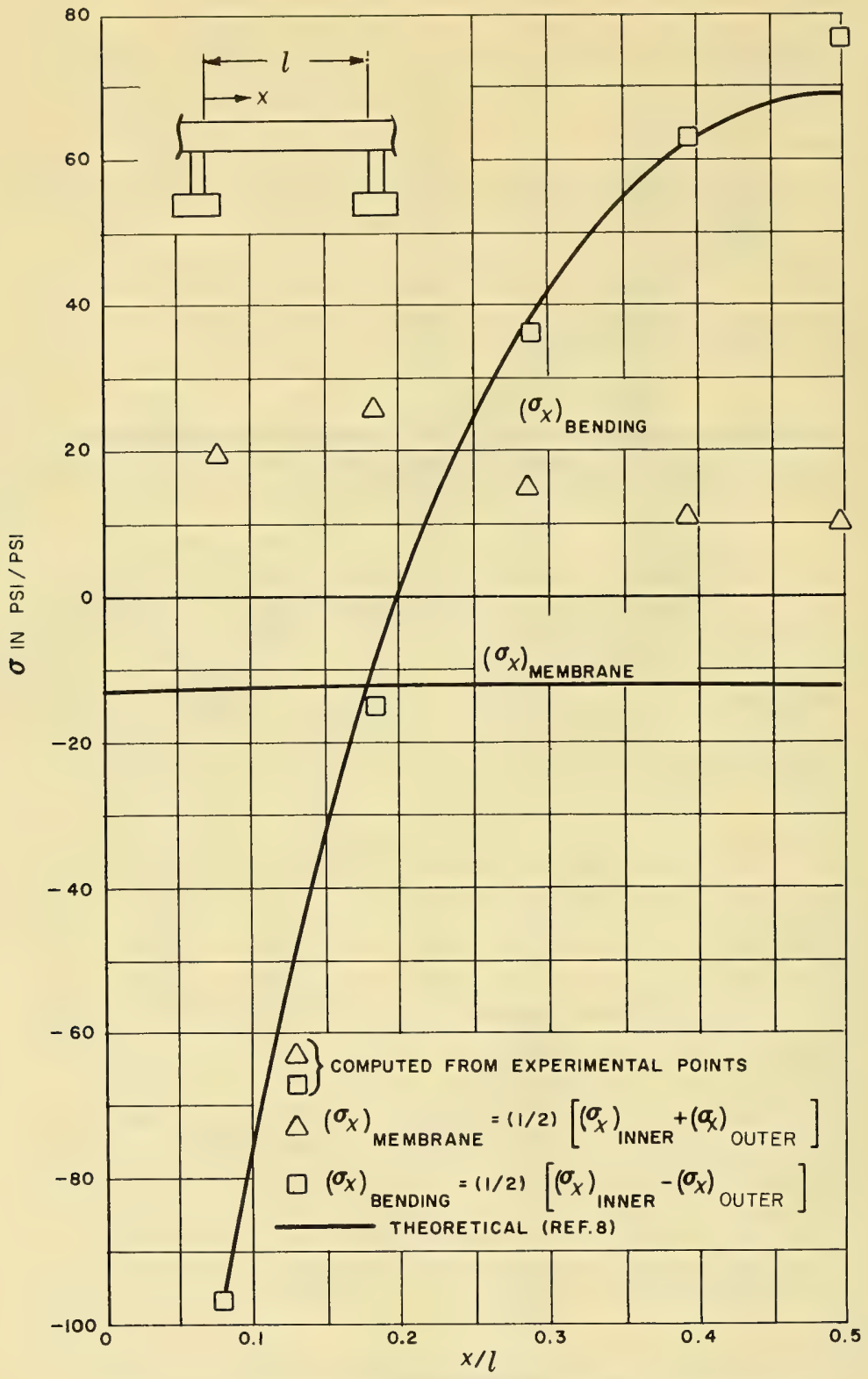

Figure 24 - Axial Membrane and Bending Stresses at the Major Axis 


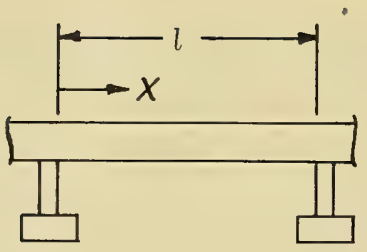
$\left.\begin{array}{l}\triangle \\ \square\end{array}\right\}$ COMPUTED FROM EXPERIMENTAL POINTS
$\triangle\left(\sigma_{X}\right)_{\text {Membrane }}=(1 / 2)\left[\left(\sigma_{X}\right)_{\text {INNER }}+\left(\sigma_{X}\right)_{\text {OUTER }}\right]$
$\square\left(\sigma_{X}\right)_{\text {BENDING }}=(1 / 2)\left[\left(\sigma_{X}\right)_{\text {INNER }}-\left(\sigma_{X}\right)_{\text {OUTER }}\right]$
THEORETICAL (REF.8)

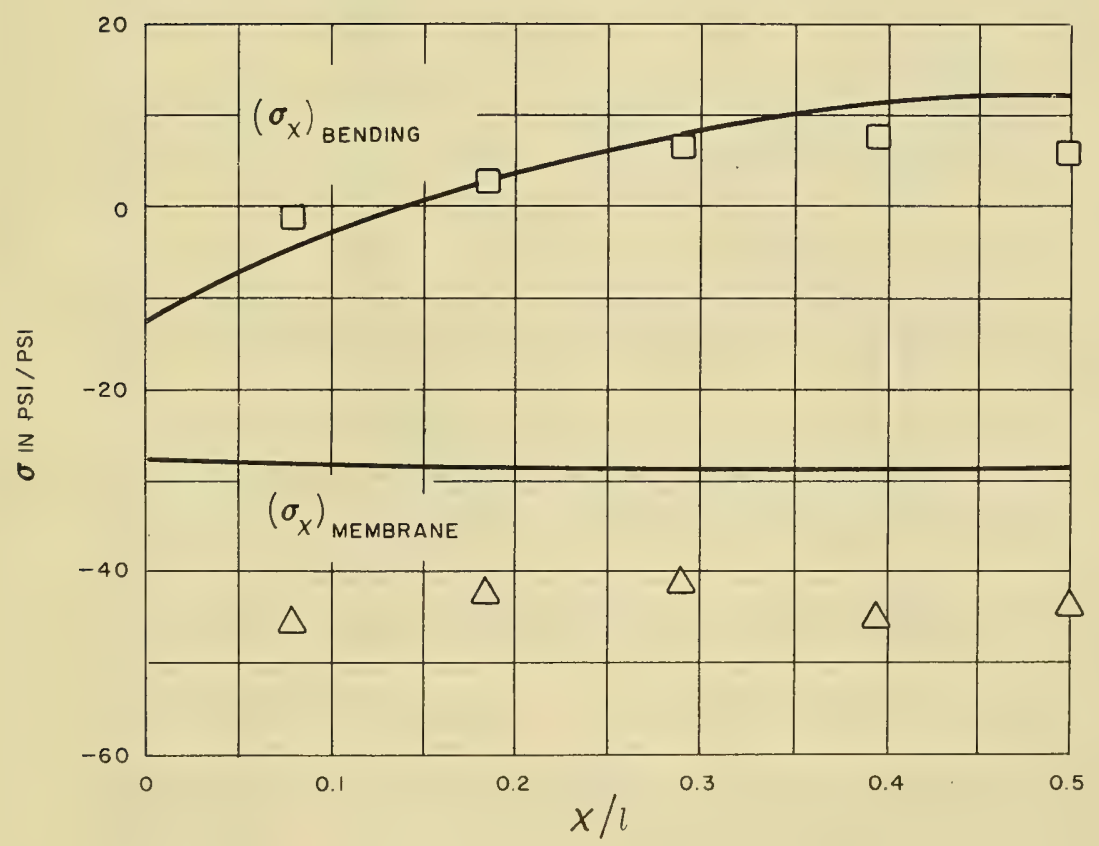

Figure 25 - Axial Membrane and Bending Stresses at the Minor Axis 


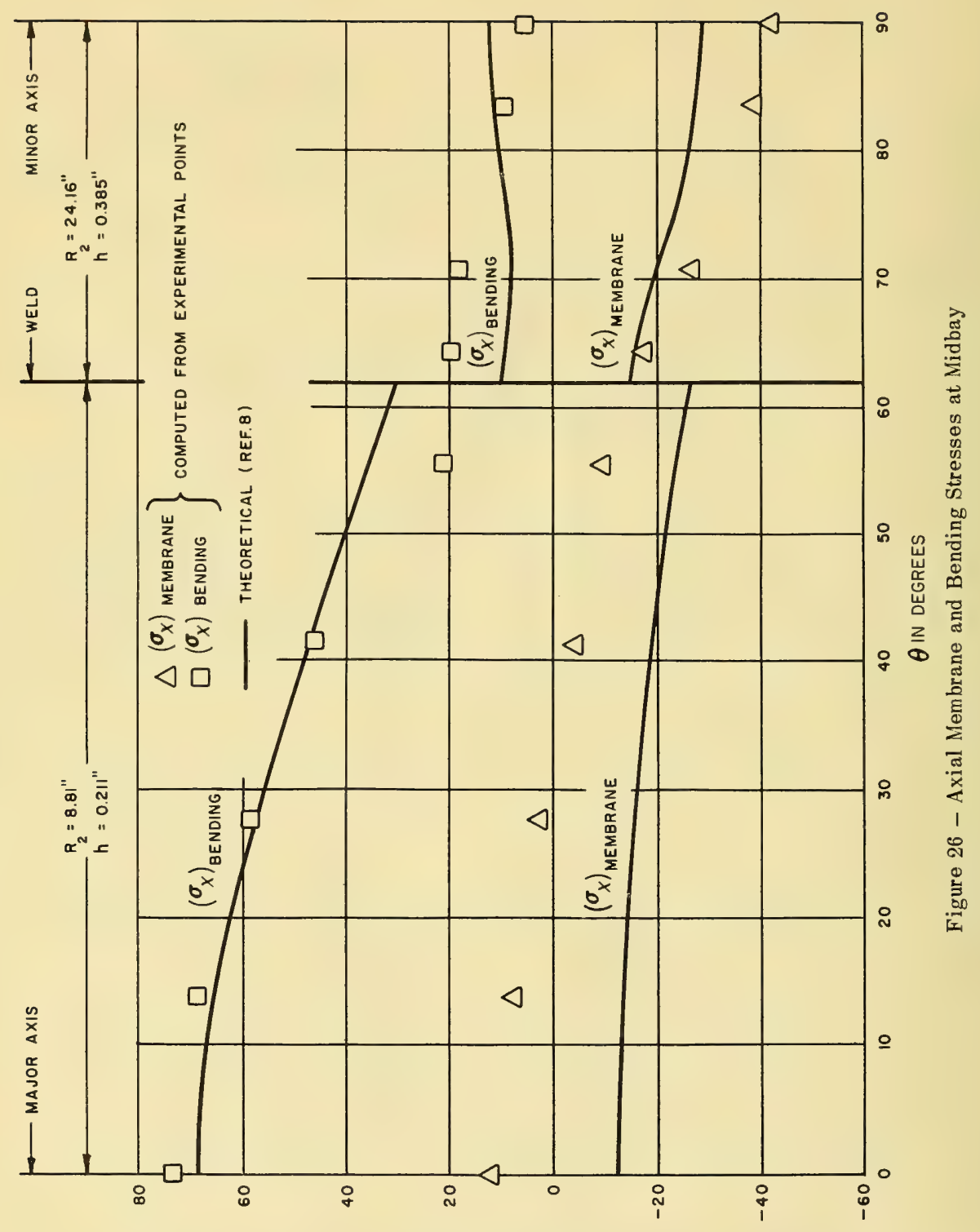

ISd/ISd NI 0 
TABLE 1

Comparison of Measured Stresses to Show Influence of Bulkhead Spacing

\begin{tabular}{|c|c|c|c|}
\hline \multirow{2}{*}{ Locations } & \multicolumn{2}{|c|}{$\begin{array}{c}\text { Stress Sensitivities } \\
\text { psi/psi }\end{array}$} & $\begin{array}{c}\text { Stress } \\
\text { Ratio }\end{array}$ \\
\cline { 2 - 4 } & Model EC-1 & Model EC-1B & $\frac{\text { EC-1 }}{\text { EC-1B }}$ \\
\hline Frame Flange - Major Axis & -149.10 & -96.30 & 1.55 \\
\hline - Minor Axis & +86.10 & +41.40 & 2.08 \\
\hline Hencky-Von Mises & & & \\
\hline Midbay - Major Axis - Inside & 85.12 & 62.40 & 1.36 \\
\hline - Outside & 52.63 & 42.95 & 1.23 \\
\hline Midbay - Minor Axis - Inside & 46.11 & 42.23 & 1.09 \\
\hline - Outside & 63.77 & 62.99 & 1.01 \\
\hline
\end{tabular}

TABLE 2

Comparison of Measured Stresses to Show Influence of Missile Tubes

\begin{tabular}{|c|c|c|c|}
\hline \multirow{2}{*}{ Locations } & \multicolumn{2}{|c|}{$\begin{array}{r}\text { Stress Sensitivities } \\
\text { psi/psi }\end{array}$} & $\begin{array}{c}\text { Stress } \\
\text { Ratio }\end{array}$ \\
\cline { 2 - 4 } & $\begin{array}{c}\text { Model EC-1B } \\
\text { (Without Tubes) }\end{array}$ & $\begin{array}{c}\text { Model EC-1A } \\
\text { (With Tubes) }\end{array}$ & $\begin{array}{c}\text { EC-1B } \\
\text { EC-1 A }\end{array}$ \\
\hline Frame Flange - Major Axis & -96.30 & -37.80 & 2.55 \\
\hline - Minor Axis & +41.40 & - & - \\
\hline Hencky-Von Mises & & & \\
\hline Midbay - Major Axis - Inside & 62.40 & 30.00 & 2.08 \\
\hline - Outside & 42.95 & 43.42 & 0.99 \\
\hline Midbay - Minor Axis - Inside & 42.23 & 29.26 & 1.44 \\
\hline - Outside & 62.99 & 24.92 & 2.53 \\
\hline
\end{tabular}




\section{BLANK}




\section{INITIAL DISTRIBUTION}

Copies

17 CHBUSHIPS

2 Sci \& Res Sec (Code 442)

1 Lab Mgt (Code 320)

3 Tech Lib (Code 210L)

1 Struc, Ship Protec, Hull Matl \& Fab (Code 341A)

1 Prelim Des Br (Code 420)

1 Prelim Des Sec (Code 421)

1 Ship Protec (Code 423)

1 Hull Des Br (Code 440)

1 Hull Struc Sec (Code 443)

2 Sub $B r$ (Code 525)

1 Hull Arrgt, Fittings, \& Preserv (Code 633)

1 Polymer, Fiber \& Pack Sec (Code 634C)

1 Pres Ves Sec (Code 651F)

2 CHONR

1 Struc Mech Br (Code 439)

1 Undersea Prog (Code 466)

$4 \mathrm{CNO}$

1 Tech Anal \& Adv Gr $(0 p$ 07T)

1 Plans, Prog \& Req Br (Op 311)

1 Sub Prog $\operatorname{Er}(0 p$ 713)

1 Tech Support $\mathrm{Br}(0 p$ 725)

20 CDR, DDC

1 CO \& DIR, USNMEL

1 CO, U.S. Naval Applied Sci Lab (Code 9350)

1 CDR, USNOL

1 DIR, USNRL (Code 2027)

1 CO \& DIR, USNUSL

1 CO \& DIR, USNEL

1 CDR, USNOTS, China Lake

2 CDR, USNOTS, Pasadena

1 Mr. J.L. Phillips P-8082

1 CO, USNUOS

2 NAVSHIPYD PTSMH

2 NAVSHIPYD MARE
Copies

1 SUPSHIP, Groton

1 EB Div, Gen Dyn Corp

1 SUPSHIP NNS

1 NNSB \& DD CO

1 SUPSHIP, Pascagoula

1 SUPSHIP, Camden

1 SUPSHIP, Quincy

1 DIR, DEF R\&E, Attn: Tech Lib

1 CO, USNROTC \& NAVADMINU, HIT

10 in C, PGSCOL, Webb

1 DIR, APL, Univ of Washington, Seattle

1 DIR, WHOI

1 NAS, Attn: Comm on Undersea Warfare

1 Prof. J. Kempner, Brooklyn Polytech Inst

1 Dr. E. Wenk, Jr., Tech Asst, The White House

1 Dr. R. DeHart, SWRI

1 Mr. L.P. Zick, Chic Bridge \& Iron Co, Chicago

1 Prof. E.0. Waters, Yale University

2 Mr. C.F. Larson, Sec'y, Welding Res Council 





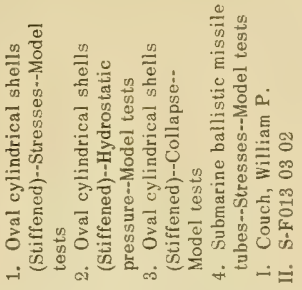

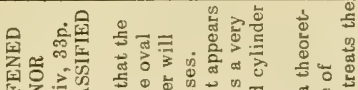

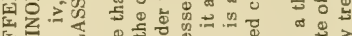

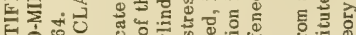

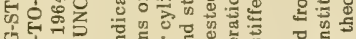

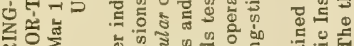

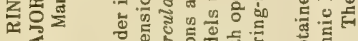

《交运

o

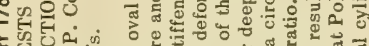

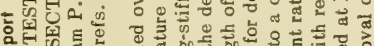

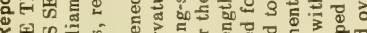

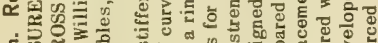

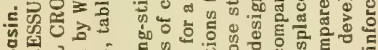

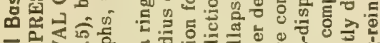

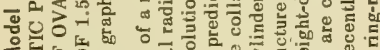

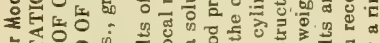

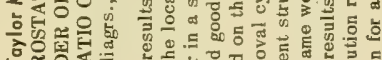

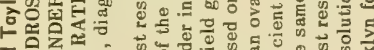

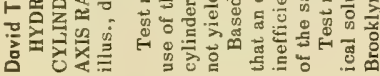

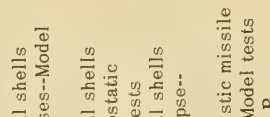

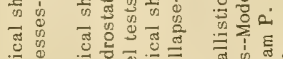

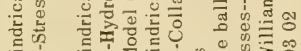

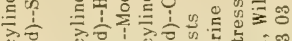

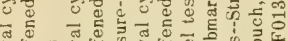

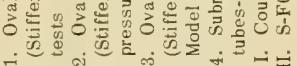

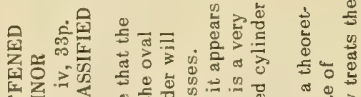

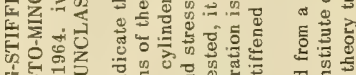

论

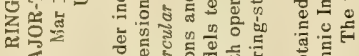

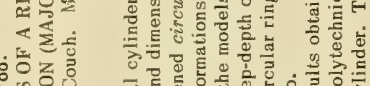

œ

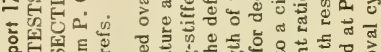

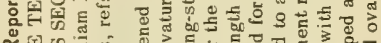

๙

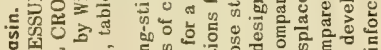

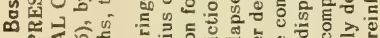

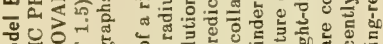

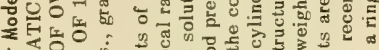

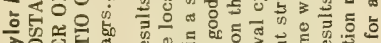

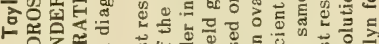

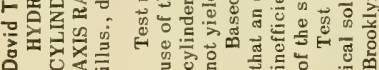

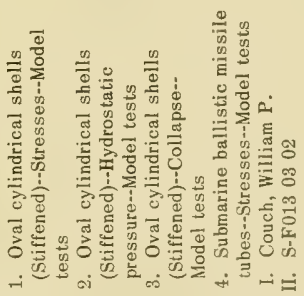

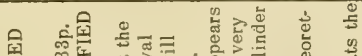

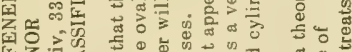

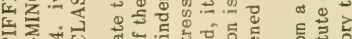

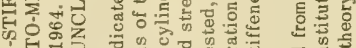

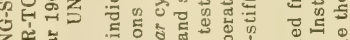

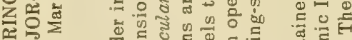

《地

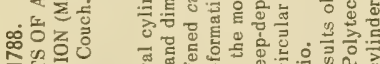

t-

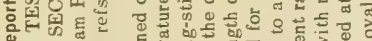

๗

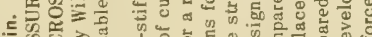

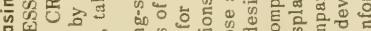

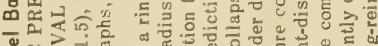

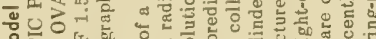

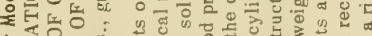

흐숭을

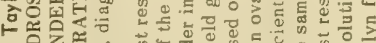

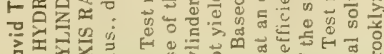

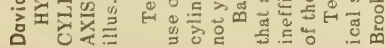

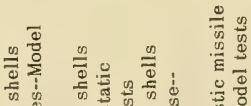

v.

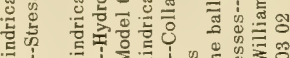

늘

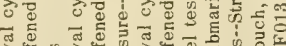

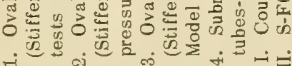

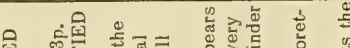

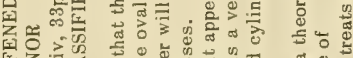

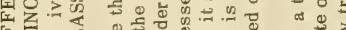

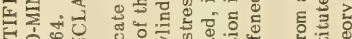

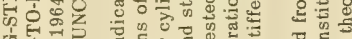

证 .

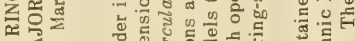

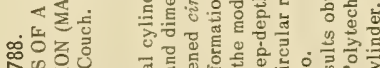

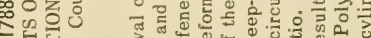

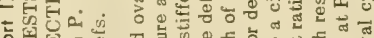

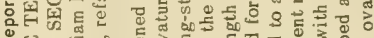

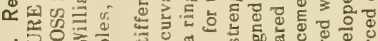

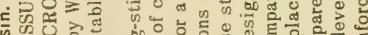

的国

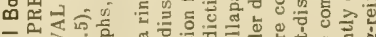

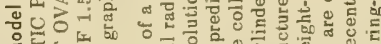

울

흔

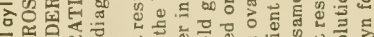

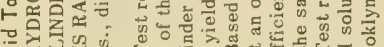

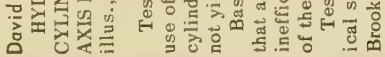



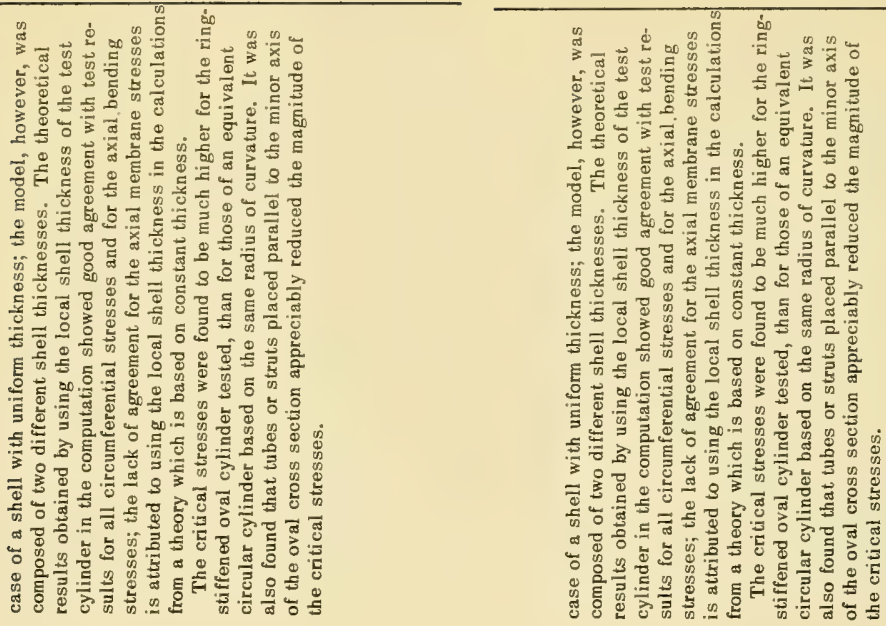

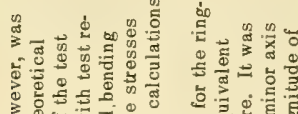

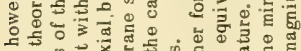

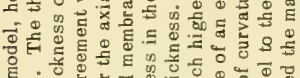

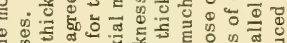

s.

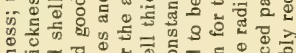

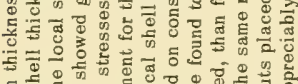

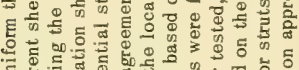

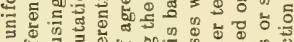

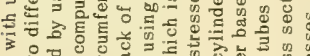

3.

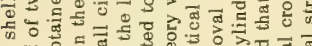

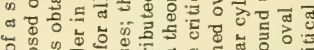

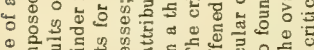

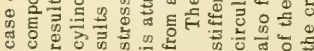

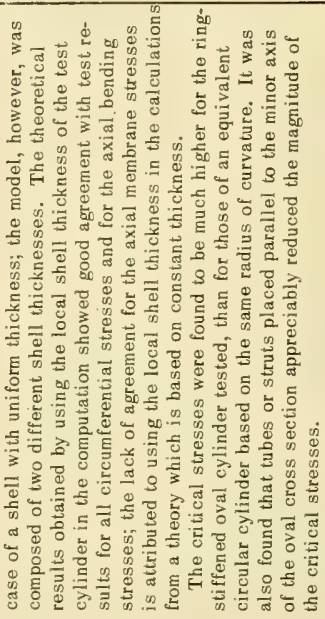




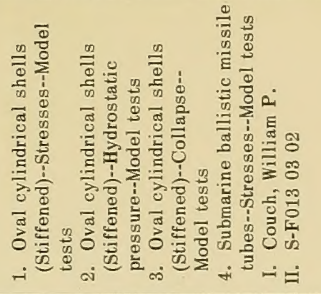

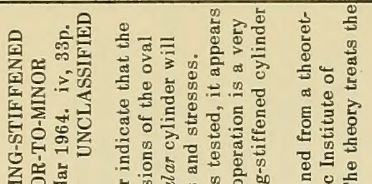

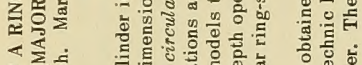

œ

地品.

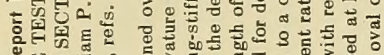

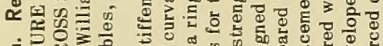

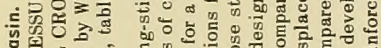

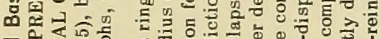

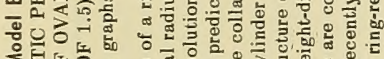

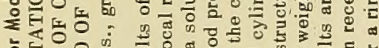

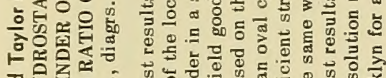

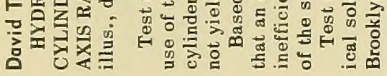

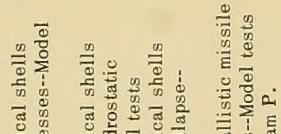

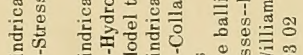

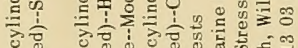

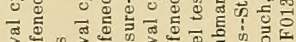

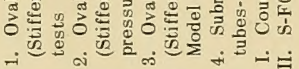

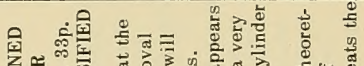

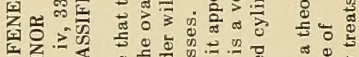

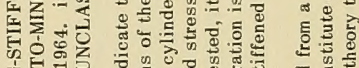

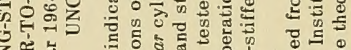

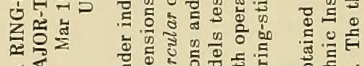

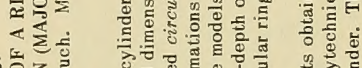

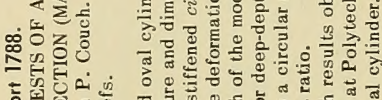

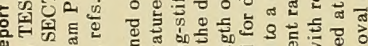

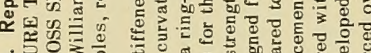

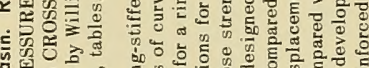

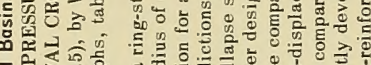

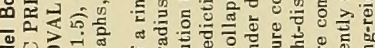

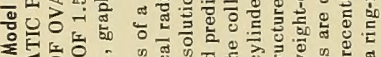

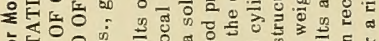

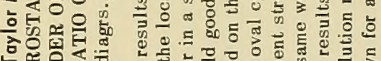

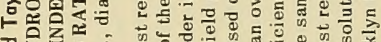

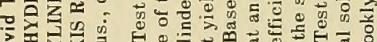

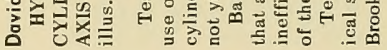

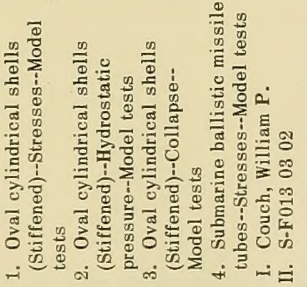

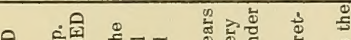

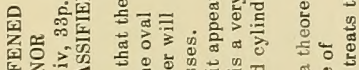

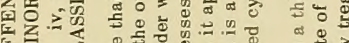

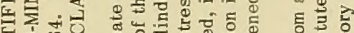

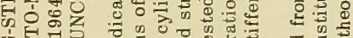

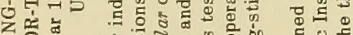

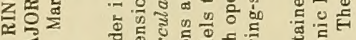

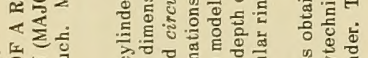

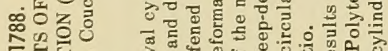

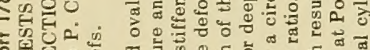

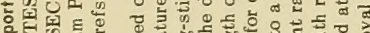

舟

O

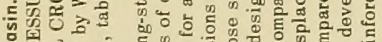

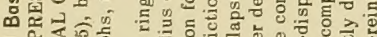

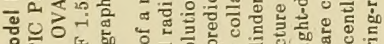

운

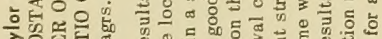

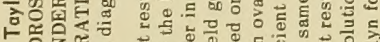

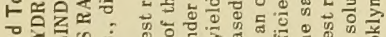

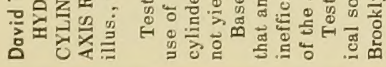

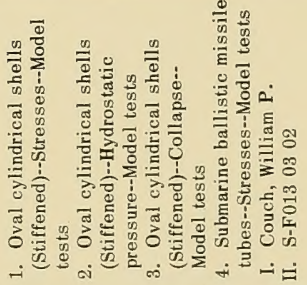

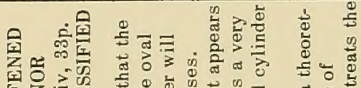

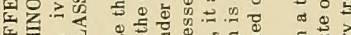

医称记

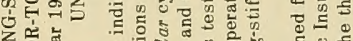

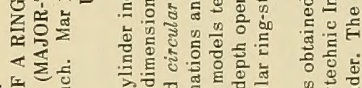

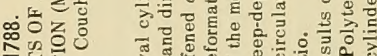

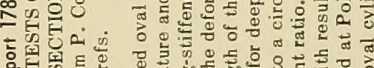

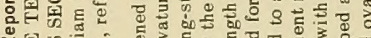

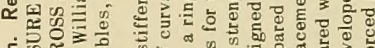

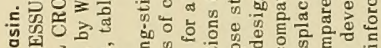

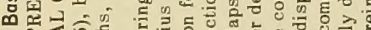

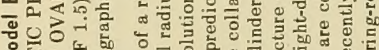

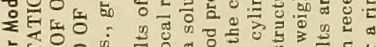

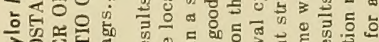

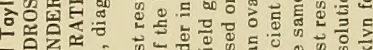

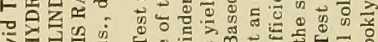

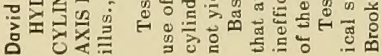



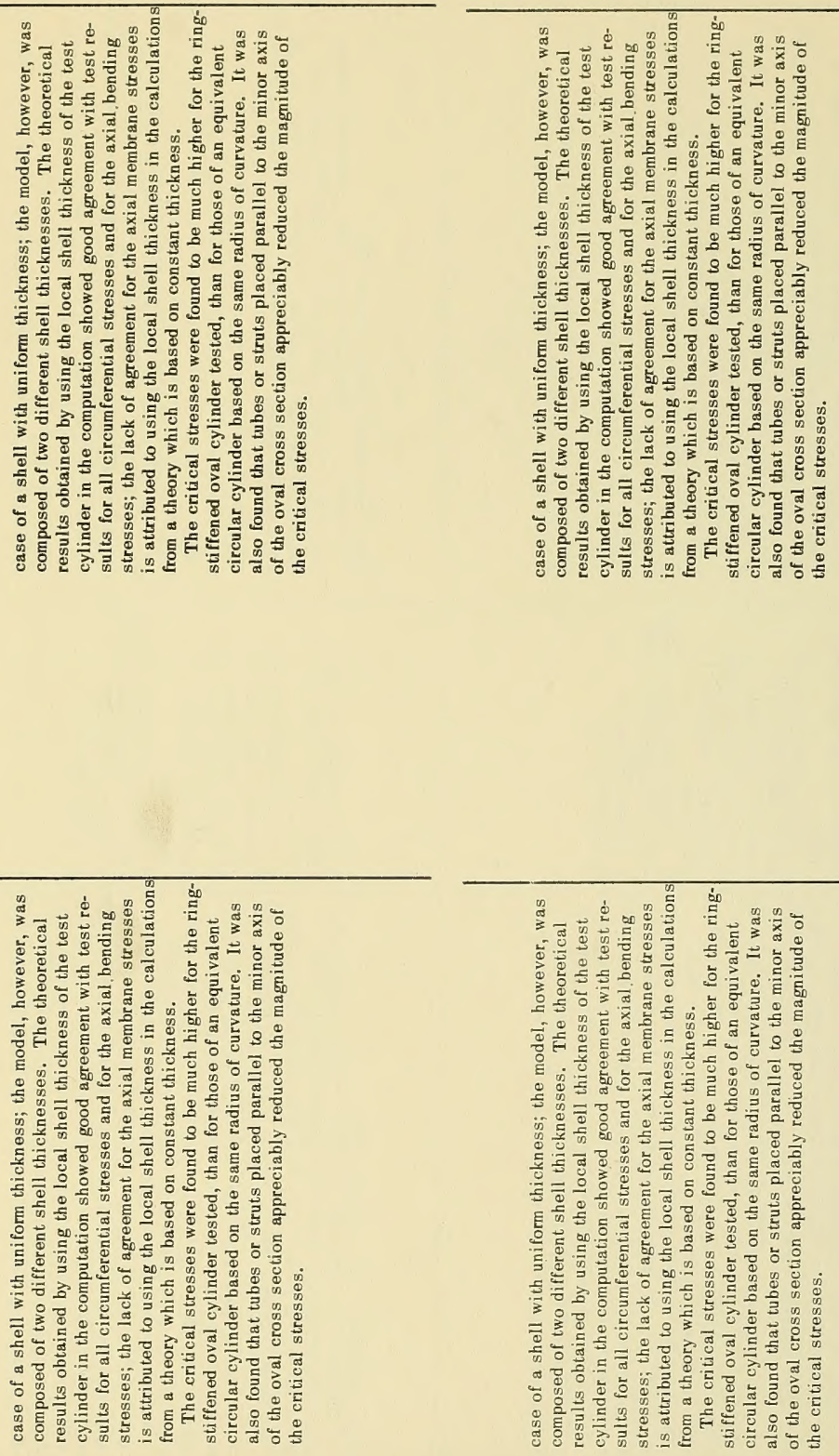

